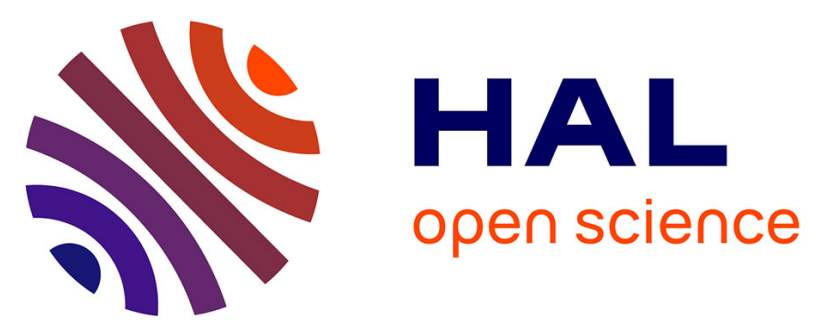

\title{
The growth-related, translationally controlled protein P23 has properties of a tubulin binding protein and associates transiently with microtubules during the cell cycle.
}

Yannick Gachet, S Tournier, M Lee, A Lazaris-Karatzas, T Poulton, U

Bommer

\section{To cite this version:}

Yannick Gachet, S Tournier, M Lee, A Lazaris-Karatzas, T Poulton, et al.. The growth-related, translationally controlled protein P23 has properties of a tubulin binding protein and associates transiently with microtubules during the cell cycle.. Journal of Cell Science, 1999, 112 ( Pt 8), pp.1257-71. hal-02381728

\section{HAL Id: hal-02381728 \\ https://hal.science/hal-02381728}

Submitted on 26 Nov 2019

HAL is a multi-disciplinary open access archive for the deposit and dissemination of scientific research documents, whether they are published or not. The documents may come from teaching and research institutions in France or abroad, or from public or private research centers.
L'archive ouverte pluridisciplinaire HAL, est destinée au dépôt et à la diffusion de documents scientifiques de niveau recherche, publiés ou non, émanant des établissements d'enseignement et de recherche français ou étrangers, des laboratoires publics ou privés. 


\title{
The growth-related, translationally controlled protein P23 has properties of a tubulin binding protein and associates transiently with microtubules during
}

\section{the cell cycle}

\author{
Yannick Gachet ${ }^{1, *}$, Sylvie Tournier ${ }^{3, \ddagger}$, Melanie Lee ${ }^{1, \S}$, Anthoula Lazaris-Karatzas ${ }^{4}$, Terry Poulton ${ }^{2}$ \\ and Ulrich-Axel Bommer ${ }^{1, \Uparrow}$ \\ Divisions of ${ }^{1}$ Biochemistry and ${ }^{2}$ Immunology, St George's Hospital Medical School, London, UK \\ ${ }^{3}$ Department of Biology, University College, London, UK \\ ${ }^{4}$ Nexia Biotechnologies, St Anne-Bellevue, Quebec, Canada \\ *Present address: Department of Biology, University College, London, UK \\ fPresent address: National Institute of Medical Research, Mill Hill, London, UK \\ §Present address: Marie Curie Research Institute, Oxted, Surrey, UK \\ ^Author for correspondence (e-mail: u.bommer@sghms.ac.uk) \\ Accepted 2 February; published on WWW 23 March 1999
}

\section{SUMMARY}

The translationally controlled protein P23 was discovered by the early induction of its rate of synthesis after mitogenic stimulation of mouse fibroblasts. P23 is expressed in almost all mammalian tissues and it is highly conserved between animals, plants and yeast. Based on its amino acid sequence, P23 cannot be attributed to any known protein family, and its cellular function remains to be elucidated. Here, we present evidence that P23 has properties of a tubulin binding protein that associates with microtubules in a cell cycle-dependent manner. (1) P23 is a cytoplasmic protein that occurs in complexes of 100-150 $\mathrm{kDa}$, and part of P23 can be immunoprecipitated from HeLa cell extracts with anti-tubulin antibodies. (2) In immunolocalisation experiments we find P23 associated with microtubules during $G_{1}, S, G_{2}$ and early $M$ phase of the cell cycle. At metaphase, $\mathbf{P 2 3}$ is also bound to the mitotic spindle, and it is detached from the spindle during metaphase-anaphase transition. (3) A GST-P23 fusion protein interacts with $\alpha$ - and $\beta$-tubulin, and recombinant P23 binds to taxol-stabilised microtubules in vitro. The tubulin binding domain of P23 was identified by mutational analysis; it shows similarity to part of the tubulin binding domain of the microtubule-associated protein MAP-1B. (4) Overexpression of $\mathbf{P 2 3}$ results in cell growth retardation and in alterations of cell morphology. Moreover, elevation of P23 levels leads to microtubule rearrangements and to an increase in microtubule mass and stability.

Key words: Translationally controlled tumour protein (TCTP), P23, Tubulin binding, Microtubule, Cell cycle, Immunolocalisation, Overexpression

\section{INTRODUCTION}

The protein P23, also referred to as 'P21' (Chitpatima et al., 1988; Yenofsky et al., 1982), 'Q23' (Thomas and Luther, 1981; Thomas, 1986) or 'translationally controlled tumour protein', TCTP (Gross et al., 1989), was discovered independently by three groups in search of translationally regulated proteins. The mRNA of ' $\mathrm{P} 21$ ' has been found to be highly represented in untranslated mRNP particles of a mouse sarcoma cell line (Yenofsky et al., 1983) and of mouse erythroleukaemia cells (Yenofsky et al., 1982). 'Q23' was discovered in Swiss 3T3 cells to be one of a number of proteins whose synthesis is drastically up-regulated after serum stimulation (Thomas and Luther, 1981; Thomas, 1986) and, later, P23 was identified as a protein whose rate of synthesis is greatly enhanced in growing versus non-growing Ehrlich ascites tumour cells (Benndorf et al., 1988; Böhm et al., 1989). Investigations in different laboratories showed that P23 synthesis is regulated at the translational level (Böhm et al., 1989, 1991; Thomas, 1986; Thomas and Luther, 1981; Yenofsky et al., 1982), and our own study demonstrated that the activity of initiation factor eIF-4E is important for P23 mRNA translation (Bommer et al., 1994). The genomic sequence of rabbit TCTP/P23 was recently published by Thiele et al. (1998). This study revealed that the 5 -flanking region of the P23 gene contains promoter elements for a variety of transcription factors, indicating that P23 expression is also regulated at the transcriptional level. Indeed, two recent reports noted considerable alterations of TCTP/P23 mRNA levels in response to changes in cellular conditions (Stürzenbaum et al., 1998; Sage-Ono et al., 1998).

The first P23 cDNA sequences from mouse (Chitpatima et al., 1988) and man (Gross et al., 1989) were published a decade ago, and recent compilations of $\mathrm{P} 23$ sequences revealed a high degree of conservation between all eukaryotic phyla (see e.g. 
Sanchez et al., 1997). P23 is a widely expressed protein, as can be seen from the compilation of EST databases where it was identified as being expressed in 26 out of 30 human tissues (Adams et al., 1995). This is in line with the results of a recent northern blot screening of 43 different human organs (B.-J. Thiele, personal communication), of immunohistochemical investigations of human cell lines and tissues (Sanchez et al., 1997) and of a western blot screening of rat organs (B. Sawitzki and U.-A. Bommer, unpublished observation). The high conservation and nearly ubiquitous expression of P23 indicated that it is an important cellular protein. However, similarity searches in protein databases did not reveal a relationship of P23 to any of the known protein families, nor did they provide any other clue to the potential function of the protein.

An 'extracellular function' of P23 has been described recently, i.e. its activity as an IgE-dependent histaminereleasing factor in connection with certain allergic diseases (MacDonald et al., 1995). Other reports indicated that P23 is involved in triggering the interleukin-4 secretion from human basophils (Schröder et al., 1996) and that P23 synthesis from basophils is increased after stimulation with IL-3 or anti-IgE (Nielsen et al., 1998). Recently, the Plasmodium falciparum homologue of P23 has been described as a possible target for the anti-malarial drug artemisinin (Bhisutthibhan et al., 1998). However, all these investigations did not address the question of the intracellular function of P23. The possibility that P23 has properties of a calcium-binding protein was suggested (Sanchez et al., 1997), based on an earlier report on the calcium-binding activity of a similar protein from trypanosomes (Haghighat and Ruben, 1992). Various papers reported the early up-regulation of P23 synthesis after growthinduction of mammalian cell lines (Thomas and Luther, 1981; Böhm et al., 1989; Bommer et al., 1994), suggesting an involvement of the protein in growth-related processes.

Here, we present both in vitro and in vivo evidence showing that P23 has properties of a tubulin binding protein. By immunolocalisation experiments we show that P23 associates with microtubules in a cell cycle-dependent manner, and that it is bound to the mitotic spindle. We demonstrate that overexpression of P23 affects both the properties of the microtubular network and cell growth and morphology.

\section{MATERIALS AND METHODS}

\section{Construction of plasmids}

The mouse P23 expression vector pT7.7-P23 was prepared by Dr M. A. Greagg in our laboratory by subcloning the mouse P23 coding region from the plasmid pRK23-3-5 into the NdeI/BamHI cloning site of the bacterial expression vector pT7.7. The plasmid pRK23-3-5 had been generated by Dr M. Gaestel after introducing an NdeI site at the start of the P23 coding region. The P23 cDNA sequence in these constructs originated from the primary clone obtained in the laboratory of Dr G. Brawerman (Chitpatima et al., 1988). The vector pGEX 2T6', which contains a suitable in-frame NdeI site at the end of the GST coding region, was kindly provided by Dr V. Baldin. The coding region of mouse P23 was cut out from the plasmid pT7.7-P23 by restriction with $N d e \mathrm{I} / \mathrm{Bam} \mathrm{HI}$ and subcloned into this vector using the bacterial strain $E$. coli JA226. The resulting plasmid pGEX-P23 was shown to express the GST-P23 fusion protein.

Truncated mutant versions of GST-P23, as represented in Fig. 4B, were generated as follows. PCR fragments comprising a $5^{\prime}$-terminal
BamHI site and a 3 '-terminal XhoI site adjacent to the P23-cDNA sequence coding for amino acid residues 1-130 (mutant P23- $\Delta 3$ ), 70130 (mutant P23- $\Delta 1 / 3$ ) and 130-172 (mutant P23- $\Delta 1 / 2$ ), respectively, were synthesised using the following pairs of primers: $5^{\prime}$ CGC GGA TCC ATG ATC ATC TAC CGG GAC CTC 3' and 5' CCG CTC GAG CGG ATT GAA ATT AGC AAG GAT 3' (mutantP23- $\Delta 3$ ); $5^{\prime}$ CGC GGA TCC GAC ATT GTC ATG AAC CAT $3^{\prime}$ and $5^{\prime}$ CCG CTC GAG CGG ATT GAA ATT AGC AAG GAT 3' (mutantP23- $\Delta 1 / 3$ ); and 5' CGC GGA TCC ACC TAC CAG TTT TTT ATT GGT GAA $3^{\prime}$ and 5' CCG CTC GAG ACA TTT CTC CAT CTC TAA GCC 3' (mutantP23- $\Delta 1 / 2$ ). The PCR-fragments were cloned in-frame with the GST coding region into the $\mathrm{BamHI} / \mathrm{XhoI}$ restriction sites of the vector pGEX 4T. The plasmid PIM4.4 (provided by Dr D. Templeton) was originally obtained by a two-hybrid screen experiment. It contains the human P23 coding sequence starting from about amino acid position 55 subcloned into the pGEX vector system. This construct is here referred to as GST-P23( $\Delta 1-55)$ and was employed as an additional, $\mathrm{N}$-terminally truncated, GST-P23 mutant protein.

\section{Protein expression and purification}

The plasmid pT7.7-P23 was transfected into E. coli BL21(DE3), and the pGEX constructs into $E$. coli JA226. The bacteria were grown overnight in brain heart broth medium and induced for 6 hours by 0.1 $\mathrm{mM}$ IPTG. Then, the cells were collected by centrifugation and homogenised by sonication. The GST-fusion proteins, as well as unconjugated GST, were purified on glutathione-agarose beads and eluted with the following buffer: $10 \mathrm{mM}$ Tris-HCl, pH 8.0, $10 \mathrm{mM}$ glutathione, $100 \mathrm{mM} \mathrm{NaCl}, 1 \mathrm{mM}$ PMSF. The proteins were then equilibrated against $10 \mathrm{mM}$ Tris- $\mathrm{HCl}, \mathrm{pH} 8.0,50 \mathrm{mM} \mathrm{NaCl}$ by gel filtration through a PD-10 column (Pharmacia). Recombinant P23 was purified from the bacterial extract by ammonium sulphate fractionation $(45-75 \%)$ followed by chromatography on DEAE Sephadex-A25 in the following buffer: $50 \mathrm{mM}$ Tris-HCl, $\mathrm{pH}$ 8.0, 1 $\mathrm{mM}$ EDTA, $0.5 \mathrm{mM}$ dithiothreitol, $1 \mathrm{mM}$ PMSF. The elution was performed using the same buffer containing $200 \mathrm{mM} \mathrm{NaCl}$. The sample was passed through a Sephadex-G50 column adjusted to the following buffer conditions: $25 \mathrm{mM}$ sodium acetate, $\mathrm{pH} 5.35,1 \mathrm{mM}$ EDTA, $0.5 \mathrm{mM}$ dithiothreitol, $1 \mathrm{mM}$ PMSF. The protein was adsorbed to an S-Sepharose column $(1 \times 5 \mathrm{~cm})$ and eluted with $80 \mathrm{mM} \mathrm{NaCl}$, all in the same buffer. Before storage in liquid nitrogen, the $\mathrm{pH}$ was adjusted to 8.0.

\section{Antibodies}

The preparation of polyclonal rabbit antibodies against peptides $\mathrm{P} 2$ (residues 98-113) and P3 (C terminus, residues 161-172) of mouse P23 was described earlier (Bommer et al., 1994). Polyclonal antibodies against murine purified recombinant P23 were raised in rabbits. All these antibodies were suitable for detecting P23 on western blots. For immunofluorescence microscopy, the rabbit antipeptide antibody (P2) was affinity-purified by chromatography on GST-P23 crosslinked to CNBr-activated Sepharose. After washing the column with PBS containing $0.5 \mathrm{M} \mathrm{NaCl}$, the antibody was eluted

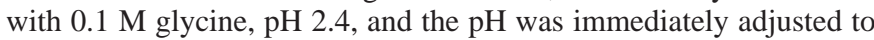
neutral with $1 \mathrm{M}$ Tris buffer, $\mathrm{pH}$ 8.0. A mouse monoclonal antibody against human TCTP/P23 was kindly provided by Dr J.-C. Sanchez (Sanchez et al., 1997). Anti-tubulin antibodies were purchased from Amersham (anti $\alpha$-tubulin) or from Sigma (anti $\alpha$-tubulin, DM 1A, and anti $\beta$-tubulin, TUB 2.1). The antibody against acetylated $\alpha$ tubulin (6-11B-1) was kindly provided by Dr P. Gordon-Weeks and the anti-GST antibody by Dr S. Goodbourn. Horseradish peroxidaseconjugated secondary antibodies against rabbit IgG were obtained from Amersham (UK) or from Dako (UK), and peroxidaseconjugated antibody against mouse $\operatorname{IgG}$ was purchased from Sigma. FITC-conjugated anti-mouse IgG and streptavidin, biotinylated antirabbit and anti-mouse IgG, TMRITC-conjugated streptavidin and mounting medium (Vectorshield) were obtained from Vector Laboratories (UK). 


\section{Cell culture and synchronisation}

Mouse NIH 3T3 fibroblasts and monkey COS-7 cells were maintained in DMEM containing 10\% foetal bovine serum and 100 units $/ \mathrm{ml}$ of streptomycin and penicillin. Bovine mammary epithelial cells were grown in the same medium with $5 \mu \mathrm{g} / \mathrm{ml}$ insulin and $50 \mu \mathrm{g} / \mathrm{ml}$ hygromycin B. HeLa-S3 cells were grown in spinner cultures in RPMI medium containing $10 \%$ foetal bovine serum and 100 units $/ \mathrm{ml}$ of streptomycin and penicillin. For cell synchronisation, COS-7 cells were treated in the following way to obtain cell populations enriched in cells in different stages of the cell cycle: cells in $\mathrm{G}_{0}$, serum starvation $(0.1 \%$ FCS $)$ for 48 hours; cells in $\mathrm{G}_{1}$, stimulation of serumstarved cells with $20 \%$ FCS for 5 hours; cells in $S$ and $\mathrm{G}_{2}$ phases, presynchronisation with $2 \mathrm{mM}$ thymidine, release for 8 hours (DMEM, $10 \%$ FCS), aphidicolin arrest and release for different periods of time; cells in mitosis, pre-synchronisation with $2 \mathrm{mM}$ thymidine, release for 8 hours, arrest with nocodazole $(0.4 \mu \mathrm{g} / \mathrm{ml})$, mitotic shake-off and release for different periods of time.

\section{Cell fractionation experiments}

HeLa-S3 cells were grown in spinner culture to a density of $3-5 \times 10^{5}$ cells per $\mathrm{ml}$, collected by centrifugation and washed in PBS. All subsequent steps were performed at $4^{\circ} \mathrm{C}$. The cells were subjected to hypotonic lysis according to the method described by Vallee and Collins (1986). Cells were resuspended in 10 times the packed cell volume of swelling solution containing $10 \mathrm{mM}$ Pipes buffer $\mathrm{pH}$ 6.9, $1 \mathrm{mM}$ EGTA, $1 \mathrm{mM} \mathrm{MgSO} 4$ and protease inhibitors (Complete ${ }^{\mathrm{TM}}$ protease inhibitor tablets, Boehringer, and $0.4 \mathrm{mM}$ PMSF) and allowed to swell for 5 minutes. The volume of the medium was then reduced to twice the packed cell volume, and the cells were lysed by about 20 strokes in a Teflon-glass Potter homogeniser under microscopical control. After lysis, $1 \mathrm{M}$ Pipes, $\mathrm{pH}$ 6.9, was added to make up the buffer concentration to $100 \mathrm{mM}$ Pipes, $1 \mathrm{mM}$ EGTA and $1 \mathrm{mM} \mathrm{MS_{4 }}$ (PEM buffer). The particulate subcellular fractions were obtained by the following subsequent centrifugation steps: 10 minutes at $600 \boldsymbol{g}$ (nuclear fraction), 15 minutes at 20,000 $\boldsymbol{g}$ (mitochondrial fraction) and 40 minutes at $150,000 \mathrm{~g}$ (ribosomal fraction) in a TL-100 benchtop ultracentrifuge. To reduce crosscontamination, the particulate fractions were resuspended and recentrifuged through a cushion of $10 \%$ sucrose in PEM buffer. The protein concentration of each fraction was estimated using the Bradford assay (Sigma) and bovine serum albumin as standard protein.

Gel filtration of the postribosomal supernatant (S-100) was performed on a Superose-6 HR10/30 column (Pharmacia) using a BioLogic chromatography system (BioRad) at $4{ }^{\circ} \mathrm{C}$. About $10 \mathrm{mg}$ of $\mathrm{S}-100$ protein were separated in a buffer containing $10 \mathrm{mM}$ Hepes, $\mathrm{pH} 7.2,50 \mathrm{mM} \beta$-glycerophosphate, $2 \mathrm{mM} \mathrm{MgCl}_{2}$ and $0.5 \mathrm{mM}$ each of EDTA, EGTA, DTT and PMSF, at a flow rate of $0.4 \mathrm{ml} /$ minute, and $0.5 \mathrm{ml}$ fractions were collected. For analysis of the distribution of P23 and tubulin, the fractions were ethanol-precipitated overnight at $-20^{\circ} \mathrm{C}$, the protein pellets were dissolved in SDS-sample buffer and equal portions were analysed by SDS-gel electrophoresis and western blotting. For comparison, $50 \mu \mathrm{g}$ of purified recombinant P23 were run separately. For calibration of the column, the elution positions of the following molecular mass markers were determined in separate runs: Blue Dextran $(2,000 \mathrm{kDa})$, thyroglobulin $(330 \mathrm{kDa})$, $\beta$-amylase $(200 \mathrm{kDa})$, alcohol dehydrogenase $(150 \mathrm{kDa})$, bovine serum albumin $(68 \mathrm{kDa})$, carbonic anhydrase $(29 \mathrm{kDa})$ and cytochrome $c(12.4 \mathrm{kDa})$.

For coimmunoprecipitation, the postmitochondrial fraction of $\mathrm{HeLa}$ cells ( $1 \mathrm{mg}$ of total protein) was incubated for 3 hours at room temperature with an anti $\alpha$-tubulin antibody (Amersham) crosslinked to protein A-Sepharose beads (ImmunoPure kit, Pierce). Protein ASepharose beads loaded with control antibodies (rabbit pre-immune serum, Sigma) were incubated in the same way. The beads were washed in TBS containing $0.5 \mathrm{M} \mathrm{NaCl}$, and the bound material was analysed by two-dimensional electrophoresis and subsequent western blotting for the presence of P23. The 2D-electrophoresis was performed according to the O'Farrell method using ampholines (Sigma) ranging from $\mathrm{pH} 2.5$ to 7 . The part of the first dimension corresponding to $\mathrm{pH}$ 3-5 was cut out and subjected to SDS-gel electrophoresis in the second dimension. The presence of P23 protein was verified by western blotting.

\section{SDS-gel electrophoresis and western blotting}

SDS-gel electrophoresis of proteins was performed using the Laemmli system. Analysis of P23 protein was performed in $12 \%$ or $15 \%$ polyacrylamide gels. For western blotting, the proteins were transferred to Immobilon-P membranes using a semi-dry apparatus and incubated with the corresponding primary antibodies, which were then labelled with peroxidase-conjugated secondary antibodies and detected using the ECL system (Amersham). For quantification, the signals on X-ray films were scanned and quantified using a Personal Densitometer SI and the ImageQuant software program (Molecular Dynamics).

For comparison of the amount of acetylated and total $\alpha$-tubulin in MAC cells, the cells were grown to near-confluency, washed with PBS and scraped directly into SDS-sample buffer containing 2\% SDS, 100 $\mathrm{mM}$ Tris- $\mathrm{HCl}, \mathrm{pH}$ 6.8, $10 \%$ glycerol, $50 \mathrm{mM}$ DTT and $0.2 \mathrm{mM}$ PMSF (Bulinski et al., 1988) and boiled immediately. Equal volumes of cell lysates were analysed by SDS-electrophoresis and western blotting, and the signals were quantified as described before. For a loading control, the blots were probed with an affinity-purified antibody against the $\alpha$-subunit of translation initiation factor eIF-2 (Bommer et al., 1988).

\section{Immunofluorescence staining}

Cells were seeded in a multi-chamber slide at an initial density of 1$5 \times 10^{4}$ cells $/ \mathrm{cm}^{2}$, grown for another 2 or 3 days and subjected to pretreatment as required for the experiment. Doubleimmunofluorescence experiments were performed as follows. Cells were washed with pre-warmed PBS, fixed with $3.7 \%$ glutaraldehyde in PBS for 15 minutes, rinsed briefly in PBS at room temperature and extracted with $1 \%$ Triton X-100 for another 15 minutes. The cells were then permeabilised with methanol at $-20^{\circ} \mathrm{C}$ overnight. To prevent the potential generation of background fluorescence by nonspecific absorption of immunoglobulins, the cells were incubated with $0.5 \%$ BSA in PBS. The cells were stained for detection of P23 with the affinity-purified antipeptide antibody (P2), and with a biotinylated anti-rabbit antibody, which was then decorated with TMRITClabelled streptavidin. The primary antibody showed a very low background staining, as seen in control experiments where the antibody was pre-incubated with either the peptide or purified recombinant P23. In bovine cells, this antibody produced a signal only when ectopically expressed murine P23 was present, which is an additional proof of its specificity. In other control experiments, normal rabbit serum (Sigma) was used instead of the anti-P23 antibody, using an equivalent dilution of immunoglobulin. For visualisation of microtubules, the cells were subsequently stained with a monoclonal anti- $\alpha$-tubulin antibody (Sigma) and with an FITC-conjugated antimouse $\operatorname{IgG}$ as secondary antibody. An unrelated mouse $\mathrm{IgG}_{1}$ monoclonal antibody (CRA3 antibody to HIV gp120) was used as a negative control in assays for anti-tubulin. All negative control assays established the low level of background fluorescence in the fixed and permeabilised cells with all fixation protocols.

Single staining experiments were performed with mouse monoclonal antibodies against either human P23 or $\alpha$-tubulin (Amersham) using the following protocol. Cells were washed with pre-warmed 0.1 M Pipes buffer, $\mathrm{pH}$ 6.9, fixed with $3.7 \%$ formaldehyde in PBS for 45 minutes, rinsed briefly in PBS at room temperature, extracted with $0.5 \%$ Triton $\mathrm{X}-100$ for another 15 minutes and washed three times in PBS. After pre-incubation for 15 minutes in $0.5 \%$ BSA in PBS, cells were incubated with the primary antibody for 1 hour and with biotinylated anti-mouse IgG and FITC-conjugated streptavidin 
for 30 minutes each, with three 5 minute washes in PBS containing $0.5 \%$ BSA after each incubation. The specificity of the staining procedure was established either by omitting the primary antibody, which yielded only an extremely low background staining, or by staining with an unrelated monoclonal antibody, against the human La-antigen (kindly provided by Dr I. Jeffrey), which displayed an exclusively nuclear staining under these conditions.

Microscopy was performed with a Zeiss confocal laser scanning microscope, type LSM-4, equipped with an 63/1.4 objective. For consistent fluorescence evaluation and measurement, the photomultiplier, filter and laser power settings were adjusted to give an image grey-scale intensity of less than 10 for negative control assays and approximately 200 for maximal positive measurements (full scale 0-255). Consistent photo-multiplier settings were maintained throughout a single series of experiments. The signal for P23 staining was usually considerably lower than that for tubulin. In order to maintain the full structural information, the P23 signal was enhanced for the display in Fig. 2. For quantitative evaluation of microtubule density per cell, the microtubule fluorescence signal and the cell area were integrated using the LSM-4 computer program. The microtubule density was then calculated as fluorescence signal intensity divided by the cell area and displayed as arbitrary units. The values for relative mouse P23 expression levels were obtained in the same way from the signal of P23 staining. The correlation between P23 expression and microtubule density per cell was tested by statistical analysis using a simple linear regression model. The data was transformed to logarithmic scale to fit the normal distribution assumption.

\section{Protein interaction experiments}

Proteins interacting with GST-P23 were investigated as follows. HeLa cell extract (100 $\mu \mathrm{g}$ total protein) was incubated for 2 hours at room temperature with $4 \mu \mathrm{g}$ of GST-P23. The GST-P23 complexes were bound to glutathione-agarose beads (30 $\mu$ l beads) in a buffer containing $10 \mathrm{mM}$ Tris- $\mathrm{HCl}, \mathrm{pH} 7.15,150 \mathrm{mM} \mathrm{NaCl}$, and $1 \mathrm{mM}$ each of EDTA, EGTA, PMSF and benzamidine. The beads were collected by centrifugation and washed with $5 \mathrm{ml}$ of the same buffer containing $0.5 \mathrm{M} \mathrm{NaCl}$. Bound proteins were analysed by SDS-gel electrophoresis and subsequent western blotting using monoclonal antibodies against $\alpha$ - and $\beta$-tubulin (Sigma).

To demonstrate the binding of P23 to microtubules, taxol-stabilised microtubules were prepared from rat brain according to the method described by Vallee (1986). Microtubules $(30 \mu \mathrm{l})$ were mixed with purified proteins $(1 \mu \mathrm{g}$ each) as indicated in the figures and incubated for 15 minutes at $37^{\circ} \mathrm{C}$ in $50 \mu \mathrm{l} \mathrm{PEM}$ buffer containing $0.1 \mathrm{mM}$ ATP and $20 \mu \mathrm{M}$ taxol (Sigma). The microtubules were collected by centrifugation for 5 minutes at $6,500 \mathrm{rpm}$ in a microfuge, the pellet was washed twice in $1 \mathrm{ml}$ of the same buffer and centrifuged each time under the same conditions. The pellets were denatured in SDSsample buffer in a total volume of $100 \mu \mathrm{l}$, and $20 \mu \mathrm{l}$ of the sample were subjected to SDS-gel electrophoresis and western blot analysis. For comparison, $50 \mathrm{ng}$ of each protein used in the assay were analysed in parallel.

\section{Expression of P23 in eukaryotic cells}

The mouse P23 coding region was subcloned from the plasmid pT7.7P23 into the eukaryotic expression vector pcDNA-3 (Invitrogen) under the control of the CMV promoter, downstream of the EcoRI site. The resulting plasmid pcDNA-3/P23 was used for transient expression of mouse P23 in COS-7 cells and for the establishment of stable expressing cell lines. Transfection was performed using Lipofectamine (Life Technologies), and the expression was verified by western blotting. To establish stable expressing cell lines, bovine mammary epithelial cells (Huynh et al., 1991) were seeded at a density of $5 \times 10^{5}$ cells per $100 \mathrm{~mm}$ dish. On the following day, the cells were transfected with the pcDNA-3/P23 plasmid or with the empty vector for control transfections. $10 \mu \mathrm{g}$ of plasmid DNA was diluted into $0.25 \mathrm{ml}$ of DMEM and mixed with a equal volume of
Lipofectamine $(20 \mu \mathrm{g}$ of lipid in $0.25 \mathrm{ml}$ DMEM). The mix was vortexed for 10 seconds, and the complexes were allowed to form for 30 minutes at room temperature. The volume was increased to $4 \mathrm{ml}$ with DMEM and the lipid-DNA mixture was applied to the cells and allowed to incubate for $16-20$ hours at $37^{\circ} \mathrm{C}$. The cells were then cultured for another 24 hours in fresh medium containing $10 \%$ FCS and $5 \mu \mathrm{g} / \mathrm{ml}$ insulin. Subsequently, the cells were selected in the same medium containing $50 \mu \mathrm{g} / \mathrm{ml}$ hygromycin B. Resistant colonies were isolated after 14 days. Mouse P23 expression was assessed by western blotting. FACS scan analysis was performed in a Becton-Dickinson fluorescence-activated cell sorter after propidium iodide staining of cells according to standard procedures.

\section{RESULTS}

\section{P23 is a cytoplasmic protein that occurs in higher molecular mass complexes and may be found in association with tubulin}

To gain insight into the functional importance of P23, we studied its intracellular distribution. Subcellular fractionation experiments revealed that $\mathrm{P} 23$ is a cytoplasmic protein that is not associated with the nuclear, mitochondrial or ribosomal fractions (Fig. 1A). This result was confirmed by centrifugation of postnuclear supernatants in the self-generating gradient material OptiPrep ${ }^{\mathrm{TM}}$ (provided by Nycomed Pharma AS, Oslo), where P23 did not focus with any of the classical cell organelle fractions (B. Sawitzki and U.-A. Bommer, unpublished observation). To investigate whether the cytoplasmic P23 might be involved in higher molecular mass complexes, we performed gel filtration experiments with a HeLa cell postribosomal supernatant (S-100) on a Superose 6 column (Fig. 1B). The results demonstrate that P23 is eluted over a fairly wide range of fractions starting significantly earlier than the elution of the pure recombinant protein. Calibration of the column showed that the P23-containing fractions correspond to a molecular mass range from about 40 to $150 \mathrm{kDa}$, whereas pure recombinant P23 elutes at about 40$60 \mathrm{kDa}$. This indicated that, in the cell, P23 occurs both free and in at least one higher molecular mass complex of 100-150 kDa. In both NIH 3T3 (result not shown) and HeLa cell extracts, the elution pattern of P23 is very similar and the abundance of P23 is usually higher in the complexed form compared to free P23. We also tested the distribution of tubulin on the same western blots (Fig. 1B), and the results showed that tubulin is present in all fractions from the void volume down to about $100 \mathrm{kDa}$. Incidentally, the last 3-4 tubulincontaining fractions, which are likely to represent dimeric tubulin, do also contain the higher molecular mass complex of P23. To investigate whether P23 might be associated with tubulin, we performed coimmunoprecipitation studies. As none of our anti-P23 antibodies is able to immunoprecipitate the protein from cell extracts, we used an anti $\alpha$-tubulin antibody crosslinked to protein A-Sepharose beads. After incubation with a postnuclear supernatant from HeLa cells, the affinity resin was washed with TBS containing $0.5 \mathrm{M} \mathrm{NaCl}$. In order to eliminate the interference by the immunoglobulin light chain, the adsorbed proteins were analysed for the presence of P23 by two-dimensional electrophoresis and western blotting. The result (Fig. 1C) shows that P23 can be precipitated with anti-tubulin antibodies, whereas no precipitation was observed with the control antibodies. However, the yield of P23 

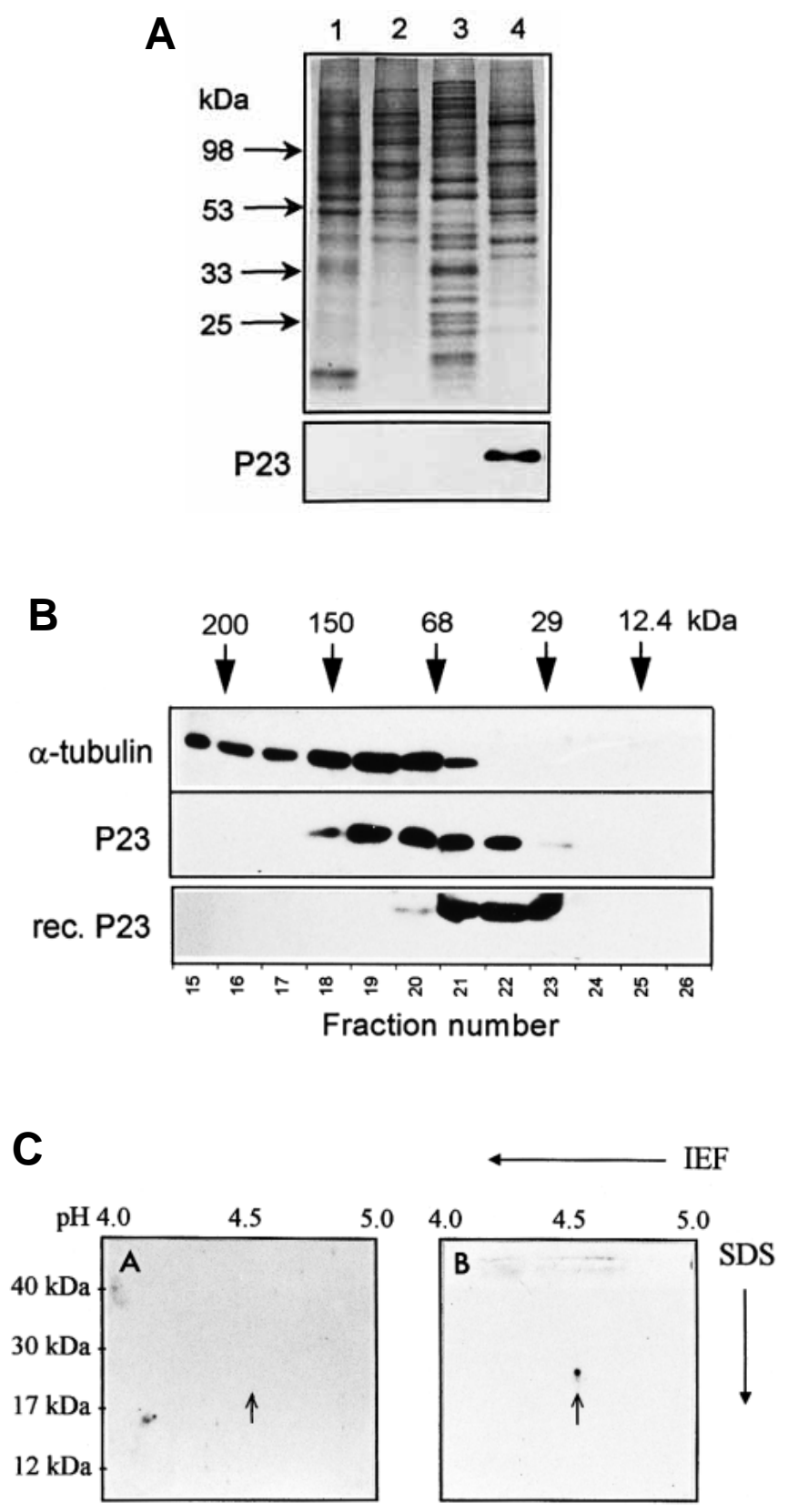

recovered under these conditions was rather low, indicating that only a proportion of P23 is associated with tubulin.

\section{P23 associates with microtubules in a cell cycle- dependent manner}

To address the question of whether P23 might be associated with microtubules, we studied its subcellular localisation in COS cells by immunofluorescence confocal microscopy. Our staining protocol employed fixation with formaldehyde or glutaraldehyde, followed by extraction with Triton X-100 to remove the excess of unbound P23 protein. For doubleimmunostaining, an affinity-purified rabbit antipeptide antibody was used to localise P23, and a mouse monoclonal antibody against $\alpha$-tubulin for microtubule staining. The affinity-purified antibody was characterised for its specificity, and control experiments verified that no cross-reactivity
Fig. 1. P23 is a cytoplasmic protein that is found in association with tubulin. (A) P23 is a cytoplasmic protein. Subcellular fractions from HeLa-S3 cells were prepared as described in Materials and methods. $40 \mu \mathrm{g}$ protein of each of the nuclear (lane 1), mitochondrial (lane 2), ribosomal (lane 3) and postribosomal (lane 4) fractions were subjected to SDS-electrophoresis and subsequent western blotting. The Coomassie Blue-stained gel after electrotransfer is shown at the top, and below is the western blot probed with an anti-P23 antibody. (B) P23 occurs in a high molecular-mass complex. The postribosomal supernatant from HeLa-S3 cells (10 mg protein) was subjected to gel filtration on a Superose- 6 column as described in Materials and methods. The fractions were analysed by SDS electrophoresis and western blotting for the presence of $\alpha$-tubulin and P23 as indicated. Arrows at the top indicate the elution positions of molecular mass marker proteins from the column. In a parallel run, the elution position of purified recombinant P23 was analysed (bottom). The fraction numbers beginning from the void volume are given below the figure. (C) P23 can be co-immunoprecipitated with tubulin antibodies. A HeLa cell extract was incubated with an anti $\alpha$ tubulin antibody coupled to protein A-Sepharose, and the bound material was analysed by two-dimensional gel electrophoresis and western blotting using an anti-P23 antibody. The western blot of the relevant part is shown here. A, control experiment using a preimmune serum for immunoprecipitation; B, immunoprecipitation with anti $\alpha$-tubulin antibodies. Arrows indicate the position of P23 protein.

occurred under the chosen conditions (see Materials and methods). For single-staining, a monoclonal antibody against human P23 was applied in parallel experiments with microtubule staining. We obtained essentially the same results with both antibodies, and examples are shown in Fig. 2.

Our initial immunolocalisation experiments revealed a cytoskeletal organisation of $\mathrm{P} 23$, similar to the one of microtubules. We asked whether the microtubule-association of P23 may change during the cell cycle. COS cells were synchronised and stained as described in Materials and methods, and Fig. 2 shows images for microtubule and P23 staining of representative cells in different cell cycle phases. The following observations have been made. (1) In serumstarved cells, the P23 staining displayed a very faint, punctate pattern with a scarce distribution of individual signals and a higher number of signals in the perinuclear area (Fig. 2b). The overall signal was considerably weaker than in cycling cells, and quantification of the fluorescence intensity per cell revealed an increase of about 3.5-fold in the microtubuleassociated P23 signal upon entry of cells into the cell cycle (results not shown). (2) A clear colocalisation of P23 with microtubules was observed in the $\mathrm{G}_{1}, \mathrm{~S}$ and $\mathrm{G}_{2}$ phases of the cell cycle (Fig. 2c-h). The signal intensity for P23 staining was considerably weaker compared to the tubulin signal, and it is enhanced in the displayed images in order to maintain the full structural information. When displayed at higher magnification, the P23 signal often appeared to be discontinuous along microtubules (not shown). (3) In early mitotic cells, we consistently observed P23 staining associated with metaphase spindles, as shown here with two different antibodies (Fig. 2k,m). However, from anaphase onwards, P23 staining was no longer microtubule-associated, and it appeared to be rather diffuse (Fig. 2o). In early postmitotic cells, the microtubule staining with the P23 antibody was very poor, similar to the picture seen in serum-starved cells (result not shown). Thus, the results presented in Fig. 2 provide clear 

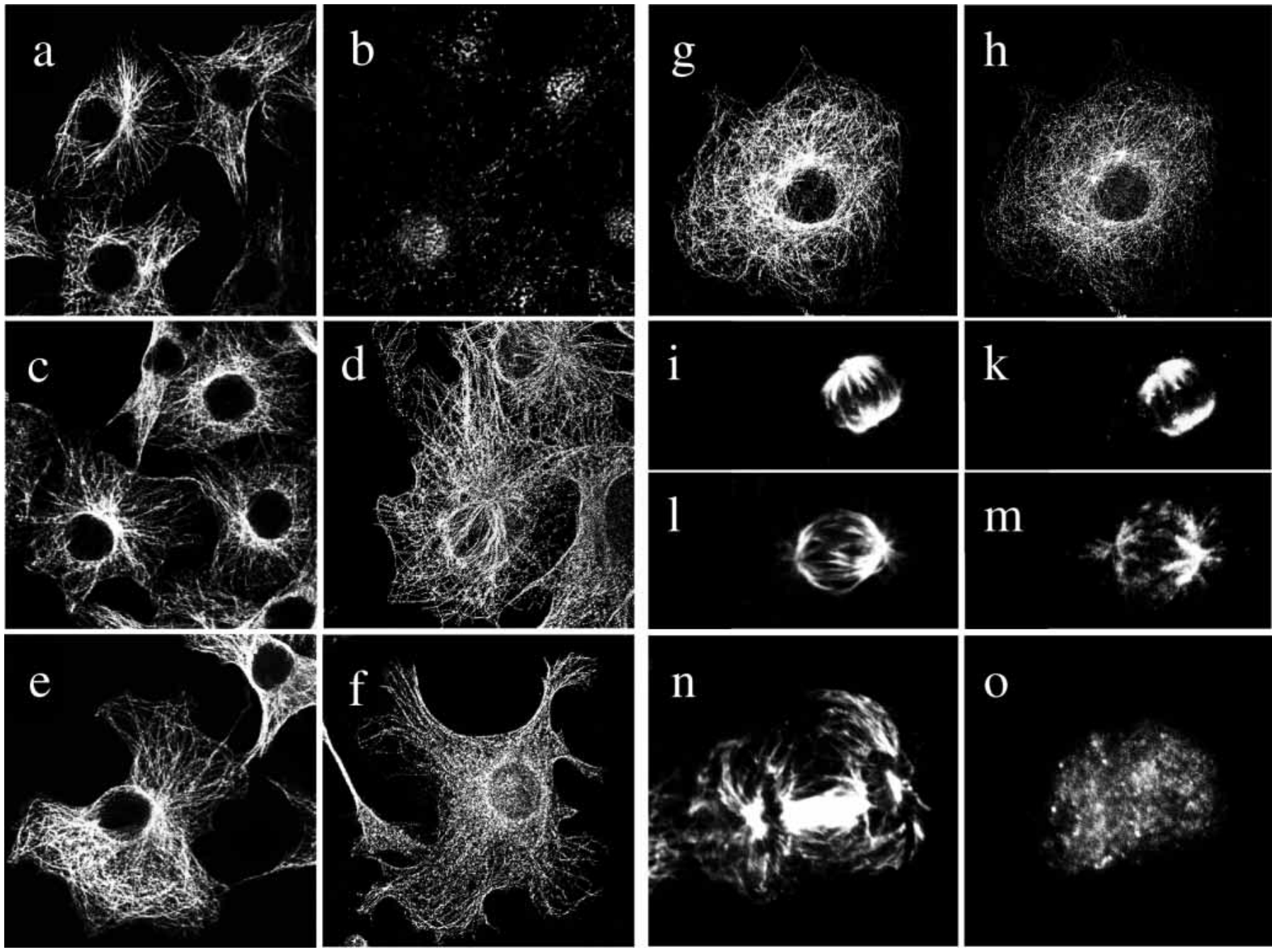

Fig. 2. P23 colocalises with microtubules in a cell cycle-dependent manner. COS-7 cells were grown on multi-chamber slides, and to obtain partially synchronised cell populations, cells were treated as described in Materials and methods. Cells were then fixed, extracted with Triton X-100 and stained separately with an antibody against $\alpha$-tubulin (a,c,e,l) or with the monoclonal anti-P23 antibody (b,d,f,m). Images of cells that were double-stained with the anti-tubulin antibody and the affinity-purified rabbit polyclonal antibody against an internal peptide of P23 are shown in $\mathrm{g}, \mathrm{h}, \mathrm{i}, \mathrm{k}, \mathrm{n}, \mathrm{o}$. Details of the procedures and antibodies are given in Materials and methods. Immunofluorescence images were obtained by confocal microscopy and are separately displayed for tubulin staining (a,c,e,g,i,l,n) and for P23 staining (b,d,f,h,k,m,o). Note that the P23 signal is enhanced compared to the tubulin signal. Representative examples of cells in the following cell cycle phases are shown: $\mathrm{G}_{0}$ $(\mathrm{a}, \mathrm{b}), \mathrm{G}_{1}(\mathrm{c}, \mathrm{d}), \mathrm{S}(\mathrm{e}, \mathrm{f}), \mathrm{G}_{2}(\mathrm{~g}, \mathrm{~h})$, early mitosis $(\mathrm{i}, \mathrm{k}, \mathrm{l}, \mathrm{m})$ and late mitosis $(\mathrm{n}, \mathrm{o})$.

evidence for a cell cycle-dependent interaction of P23 with microtubules in vivo. P23 is found in association with microtubules during $G_{1}, S, G_{2}$ and early $M$ phases of the cell cycle, whereas no such association could be observed in the late mitotic phases and in serum-starved cells.

\section{P23 has properties a tubulin binding protein}

To examine the ability of P23 to bind to tubulin in vitro, we constructed a bacterial expression plasmid for a GST-P23 fusion protein. The fusion protein and a GST control protein were expressed and purified from E. coli. The purified proteins were incubated with a postnuclear supernatant from HeLa cells and bound to glutathione-agarose beads. The beads were washed and bound proteins were analysed for the presence of tubulin by western blotting. The results shown in Fig. 3A demonstrated that GST-P23 is able to interact with $\alpha$ - and $\beta$ - tubulin from a HeLa cell extract. Neither protein bound to the GST control protein, and we did not observe binding of actin to GST-P23 under these conditions (result not shown).

We then examined the ability of P23 to bind to polymerised microtubules. Taxol-stabilised microtubules were incubated with purified recombinant $\mathrm{P} 23$ proteins from different species (mouse, human and yeast) and with GST as a control. The microtubule pellets were collected by centrifugation, washed and analysed for the presence of P23 by western blotting using the appropriate antibodies. The results (Fig. 3B) show that the recombinant P23 protein preparations from different species bound to rat brain microtubules, whereas no binding was observed in the case of the GST control protein. No P23 protein was pelleted in the absence of microtubules (result not shown).

We then asked the question whether the $\mathrm{P} 23$ protein contains a specific domain which might be responsible for tubulin 

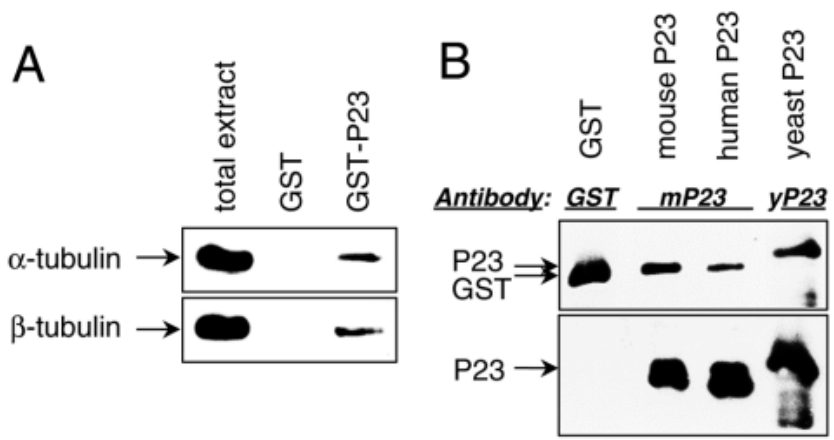

Fig. 3. Interaction of $\mathrm{P} 23$ with tubulin and microtubules. (A) Tubulin binds to a GST-P23 fusion protein. Purified GST and GST-P23 proteins were incubated with a HeLa cell postnuclear supernatant and bound to glutathione-Sepharose beads. Bound proteins were analysed by SDS-gel electrophoresis and western blotting. Immunodetection was performed with anti $\alpha$-tubulin and $\beta$-tubulin antibodies as indicated. In the first lane, $50 \mu \mathrm{g}$ of total HeLa cell extract was loaded as a control. (B) Recombinant P23 binds to taxolstabilised microtubules in vitro. Taxol-stabilised microtubules were incubated with the following purified recombinant proteins as indicated: GST and P23 from mouse, humans and yeast (Saccharomyces cerevisiae). The microtubules were collected by centrifugation, washed and analysed by SDS-gel electrophoresis and western blotting. The upper panel shows a western blot of the purified proteins before binding, and the lower panel shows a western blot of the microtubule pellets. Antibodies used for probing of both blots are indicated at the top. Note that the mobility of the yeast P23 is slightly reduced compared to the mammalian P23.

binding. As both tubulin (pI 4.8/5.3) and P23 (pI 4.5) are acidic proteins, any non-specific binding via electrostatic interactions is unlikely. However, plotting the distribution of charged amino acids within the P23 sequence revealed a polarisation of the molecule into two acidic regions (domain 1, amino acids 1-78, and domain 3, amino acids 124-172) separated by a basic region (amino acids 79-123, referred to as domain 2) (Fig. 4A). A search for sequence similarities to the basic domain of P23 revealed similarity to part of the tubulin binding domain of the microtubule-associated protein MAP-1B (Fig. 4A). The sequence of the basic domain is highly conserved among the known mammalian P23 sequences. Although the overall identity with the corresponding MAP-1B sequence is only $33 \%$ (similarity 46\%), there is a remarkable similarity in the distribution of charged amino acids, particularly of lysine and glutamic acid residues. To investigate whether the basic region represents the tubulin binding domain of P23, we generated a set of GST-P23 mutant protein constructs truncated in the three domains of the P23 protein (Fig. 4B). These mutant proteins were expressed, purified from bacteria, and verified by western blotting using antipeptide antibodies directed against different parts of the P23 sequence (results not shown). The ability of these proteins to bind tubulin was tested in the assays described above. The binding assay using HeLa cell extract as a source of tubulin revealed that only those GST-P23 constructs bearing the basic domain were able to bind $\alpha$ - and $\beta$-tubulin (Fig. 4C). Moreover, only these constructs bound to taxol-stabilised microtubules (Fig. 4D). We concluded that this domain of P23 is both necessary and sufficient to confer tubulin binding activity.

\section{Overexpression of P23 leads to alterations in cell growth and morphology}

In order to investigate whether alteration of the intracellular P23 levels may affect the microtubular cytoskeleton and cell growth, we performed overexpression experiments. We subcloned the coding region of the mouse P 23 cDNA into the pcDNA-3 vector under the control of the CMV promoter. We chose bovine mammary epithelial cells (MAC cells; Huynh et al., 1991) for these experiments, which have the advantage that the ectopically expressed mouse P23 can be distinguished from the endogenous bovine P23 by a specific antipeptide antibody (Fig. 5A). We transfected two lines of these cells: one line, here referred to as MAC-A, had been immortalised by the large T antigen, whereas the second line (MAC-B) represents a spontaneously immortalised cell line. Both lines were transfected with the P23 expression vector and with the empty vector for control. Five mouse P23-expressing cell lines were cloned from each parental cell line after selection on hygromycin B. Two clones with high P23 expression levels, referred to as MAC-A/23-1 and MAC-B/23-5, and the corresponding vector control cell lines, MAC-A and MAC-B, were chosen to perform the experiments below. By western blotting, the average P23 levels in these two cell lines were estimated to be about twofold higher than the endogenous P23 levels of the control cell lines (Fig. 5A). This indicates that much higher expression levels cannot be achieved in stable expressing cell lines.

P23-overexpressing cells displayed a much slower growth rate compared to their parental counterparts (Fig. 5B). Calculation of the growth parameters from these curves showed that upon P23 overexpression, the doubling time increased threefold in MAC-A cells and twofold in MAC-B cells. Other clones which expressed lower levels of murine P23 displayed a more moderate reduction in the growth rate (results not shown), indicating that the growth rate is inversely related to the level of expression of murine P23. Increase in P23 levels also resulted in alterations of cell morphology (Fig. 5Ca-d). In both cell lines investigated here, P23 overexpression led the cells to adopt a very elongated cell shape $(b, d)$, clearly different from the morphology of the parental cells $(\mathrm{a}, \mathrm{c})$. In less confluent cultures, we also observed a higher variability of cell shape and the tendency to an increased cell size, the latter being confirmed by FACS scan analysis (Fig. 5D). The FACS scan investigations also showed that a higher percentage of cells is in the $\mathrm{G}_{2} / \mathrm{M}$ phase of the cell cycle (Fig. 5D). This result indicated that a distortion of the cell division process could be involved in causing the growth inhibitory effect.

\section{Overexpression of P23 affects the microtubular cytoskeleton}

The observed morphological alterations in P23-overexpressing cells indicated that changes in the microtubular cytoskeleton might be involved. Therefore, we investigated whether elevation of P23 levels affected features of the microtubular network. Microtubules in P23-overexpressing cells (MAC$\mathrm{B} / 23-5$ ) and control cells (MAC-B) were visualised by immunofluorescence staining and confocal microscopy, and representative images are shown in Fig. 6Aa,c. Comparison of the microtubule patterns between the two cell lines showed that, in the P23-overexpressing cells, the microtubules were preferentially arranged in parallel rather than in a radial 
manner, with a fairly dense packaging, similar to microtubule bundling.

For quantitative analysis of microtubule density, MACB/23-5 cells were double-stained for microtubules and murine $\mathrm{P} 23$. The images of individual cells were assessed for the total fluorescence intensities of microtubules and $\mathrm{P} 23$, respectively. The results shown in Fig. 6B demonstrate that, on average, MAC-B/23-5 cells displayed a 30-40\% higher density of microtubules compared to the parental cells. To establish a correlation between microtubule density and P23 levels, cells were grouped into low, medium and high 'expressers', and the average microtubule densities of the different groups were plotted in Fig. 6B. Statistical analysis of the complete data set using a linear regression model proved that the increase in microtubule density related positively to the increase of mouse P23 expression levels $\left(y=0.29 x-2.67\right.$; ANOVA, $F_{1,22}=14.02$, $\left.P<0.001 ; r^{2}=0.389\right)$. The graphical display demonstrating this correlation is shown in the lower panel.

To determine whether elevation of P23 levels affected microtubule stability, we investigated the protection of microtubules in MAC-B and MAC-B/23-5 cells against nocodazole-induced destabilisation. After treatment with nocodazole, the cells were subjected to microtubule-staining and confocal microscopy. Representative images are shown

A

Basic Amino Acids
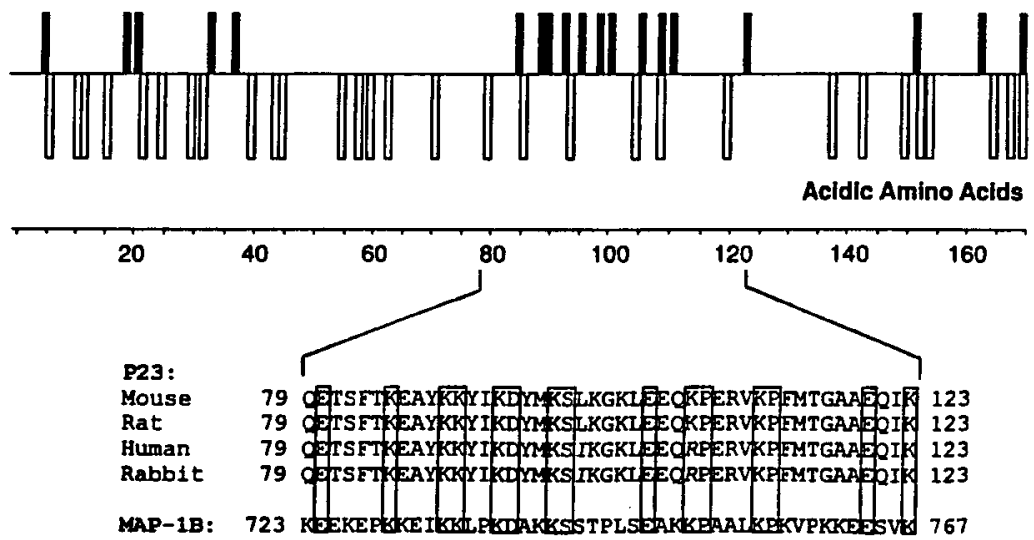

B

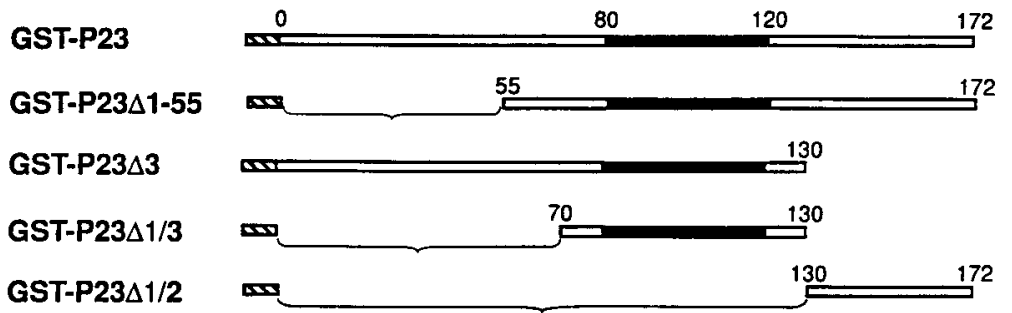

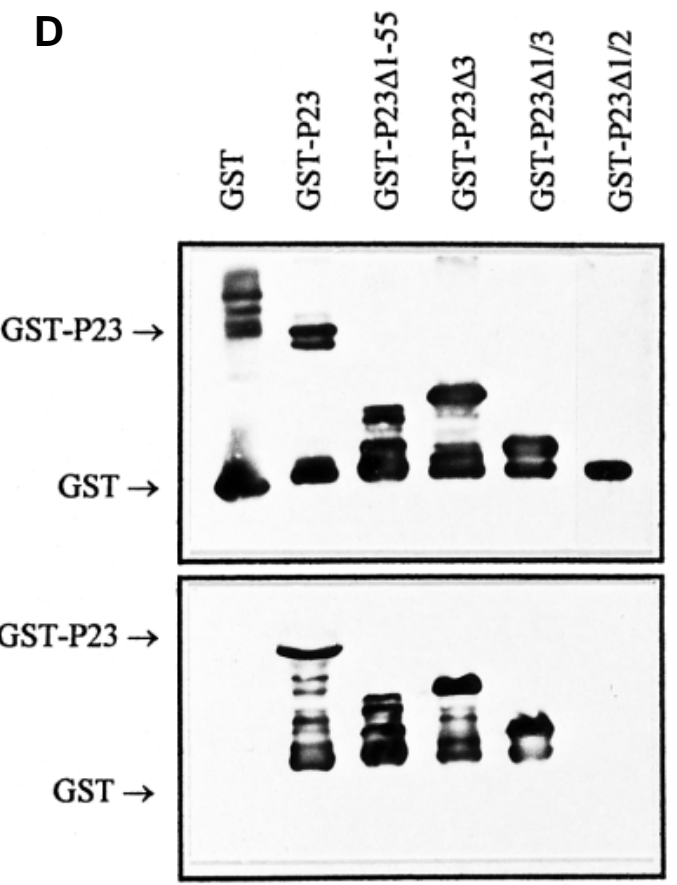

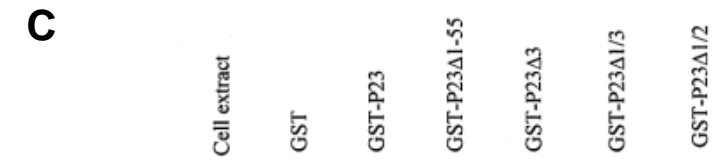
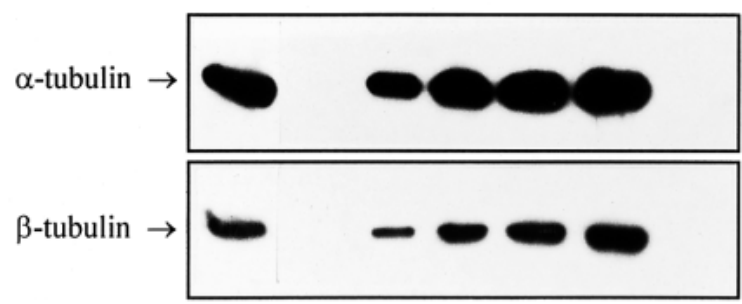

Fig. 4. Characterisation of the tubulin binding domain of P23. (A) P23 contains a basic domain similar to part of the tubulin binding region of MAP1B. The histogram shows the distribution of basic and acidic amino acids within the P23 sequence. The sequence comparison below demonstrates the conservation of the basic domain among mammalian P23 sequences and its similarity to a partial sequence within the tubulin binding region of human MAP-1B (GenBank accession number: L 06237). Identical residues are boxed. Amino acids in the human/rabbit P23 sequence which differ from the mouse/rat sequences (positions 93 and 107) are shown in italic. GenBank accession numbers of P23 sequences are: X 06407 (mouse), U 20525 (rat), X 16064 (human) and Z 46805 (rabbit). (B) Schematic representation of the truncated GST-P23 fusion proteins. Bars represent the part of the P23 amino acid sequence present in the mutant protein. The filled portion of the bar highlights the putative tubulin binding domain. The hatched bar indicates the C-terminal end of the GST portion. (C) Interaction of mutant GST-P23 fusion proteins with tubulin. The mutant proteins represented in B were incubated with HeLa cell extract and bound to glutathione-agarose beads. The beads were washed and analysed for binding of $\alpha$ - and $\beta$-tubulin by SDS-gel electrophoresis and western blotting. The different GST fusion proteins are indicated in the individual lanes. (D) Binding of mutant GST-P23 fusion proteins to taxol-stabilised microtubules. Microtubules were incubated in the presence of the mutant GST-P23 fusion proteins as indicated in the individual lanes. The microtubules were collected by centrifugation, washed and analysed by SDS-gel electrophoresis and western blotting. Upper panel, probing of the GST-fusion proteins before binding; lower panel, probing of microtubule-bound material. The blots were probed with anti-GST antibodies. 

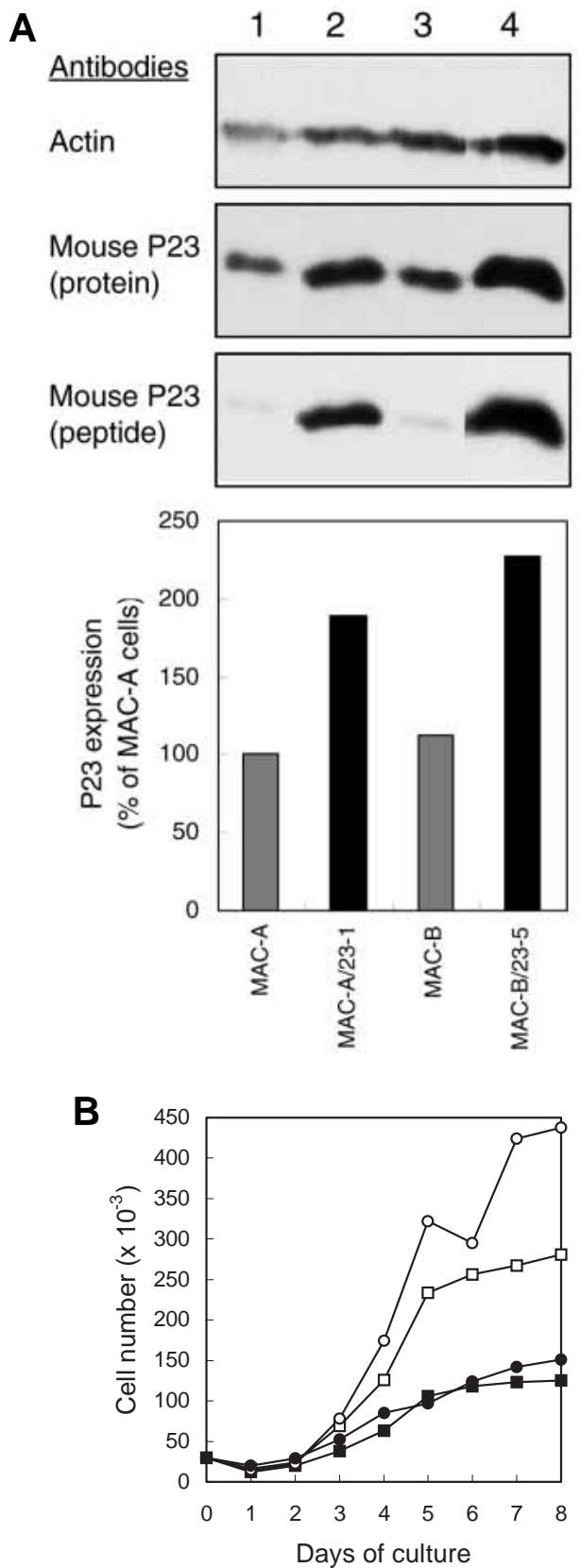

Fig. 5. Overexpression of $\mathrm{P} 23$ in bovine MAC-T cells results in alterations of cell growth and morphology. The following mouse P23-expressing cell lines were established from bovine mammary epithelial cells as described in the text: MAC-A and MAC-B (vector control cells) and MAC-A/23-1 and MAC-B/23-5 (mouse P23-expressing cells). (A) Assessment of P23 expression levels. Cell extracts (8 $\mu \mathrm{g}$ protein each) were analysed for P23 protein levels by western blotting: MAC-B (lane 1), MAC-B/23-5 (lane 2), MAC-A (lane 3) and MAC-A/23-1 (lane 4). The western blots were probed with the indicated antibodies. The antibody against recombinant mouse P23 protein detects both the endogenous and the murine P23, whereas the anti-peptide antibody specifically detects the expressed mouse protein. The graph below shows a quantitative analysis of the P23 levels from the blot developed with the antibody against the complete P23 protein. The signals were quantified and the intensity of the P23 signal was normalised against the corresponding actin signal. The relative P23 protein levels were plotted setting the value for the MAC-A cell line as 100\%. Open bars, control cell lines; filled bars, P23-overexpressing lines. (B) Elevation of P23 levels results in a slow-growth phenotype. The graph shows growth curves of all four cell lines. Cells were seeded at a density of $3 \times 10^{4}$ cells per well in 24-well plates, grown for up to 8 days and counted daily in a haemocytometer. Open symbols: control cells, MAC-A (circles) and MAC-B (squares); filled symbols: cell lines expressing murine P23, MAC-A/23-1 (circles) and MAC-B/23-5 (squares). A representative of three independent experiments is shown. (C) P23 overexpression results in morphological alterations. Phase-contrast microphotographs of control cells and of mouse P23-expressing cell lines are shown. a, MAC-A cells; b, MAC-A/23-1 cells; c, MAC-B cells; d, MAC-B/235 cells. Bar, $100 \mu \mathrm{m}$. (D) FACS scan analysis of MAC-A and MAC-B cell lines. Left, the distribution of cells between cell cycle phases (open bars, vector control cells; filled bars, P23-overexpressing cells). Right, the cell size distribution of the same cell lines (clear area, vector control cells; shaded area, P23overexpressing cells).
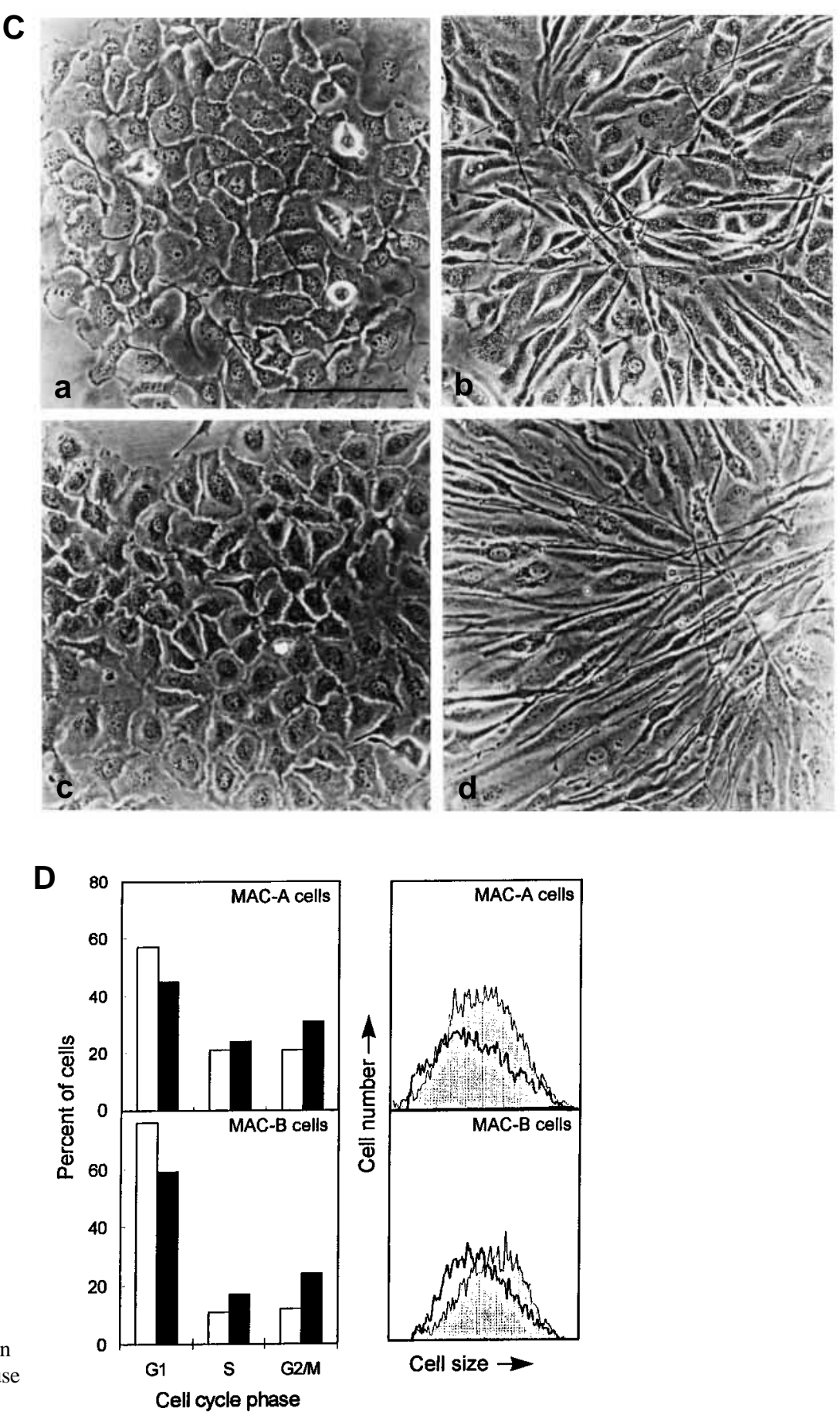

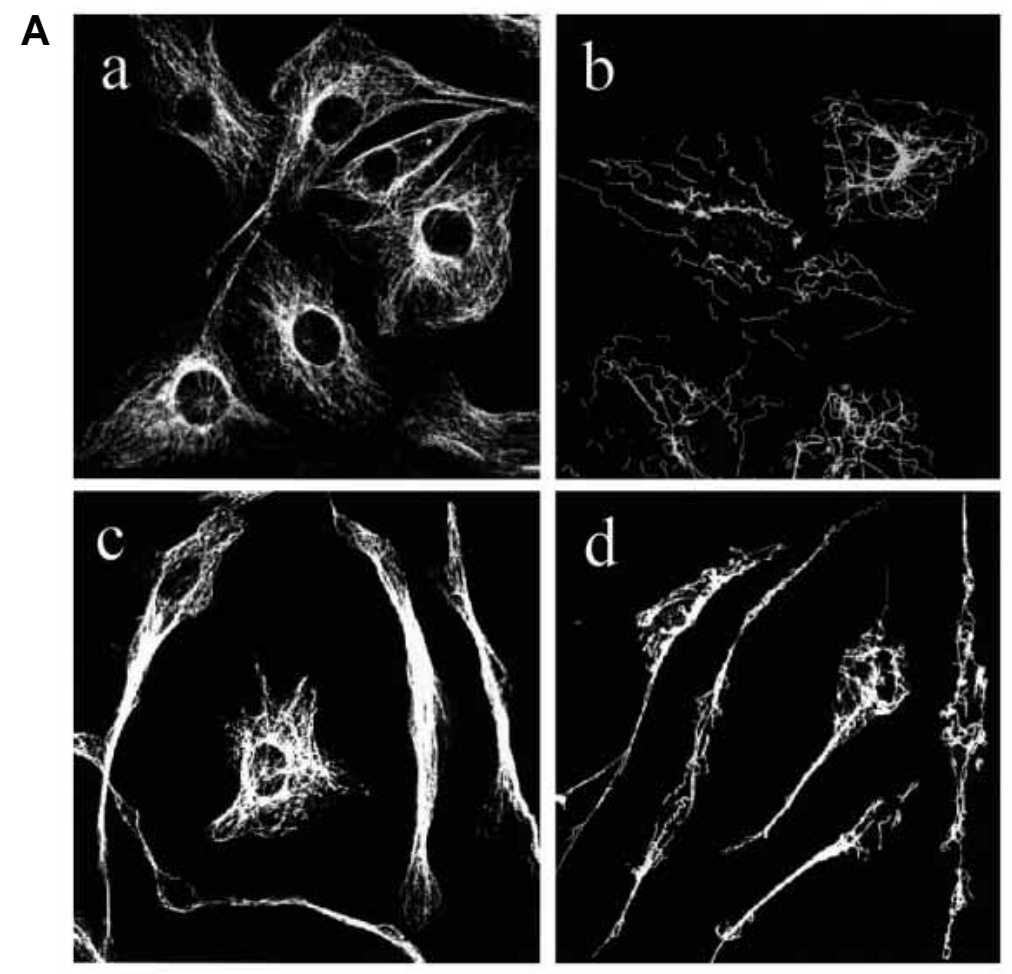

B
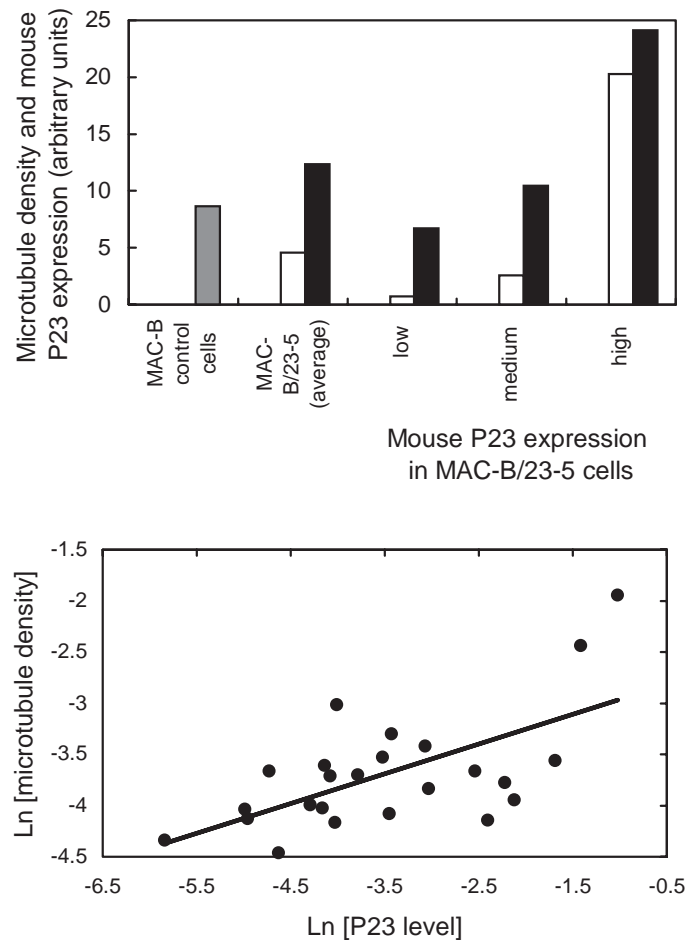

D
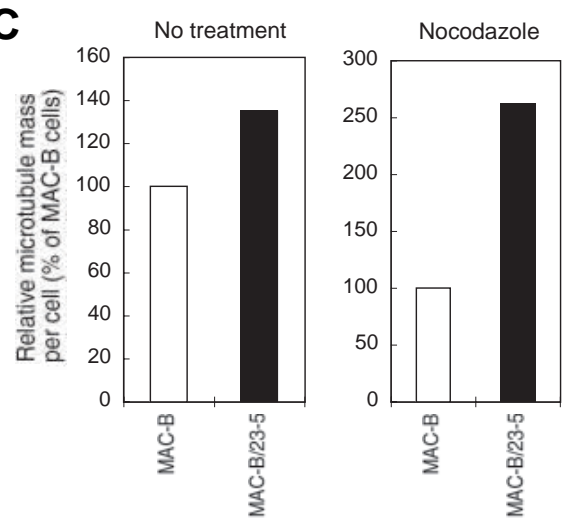

alterations in microtubule arrangement, mass and stability.

(A) Immunofluorescence images of microtubules in P23-overexpressing cells. Control cells MAC-B (a,b) and P23-overexpressing cells MAC-B/23-5 $(\mathrm{c}, \mathrm{d})$ were grown on multi-chamber slides. The cells were fixed, extracted with $1 \%$ Triton $\mathrm{X}-100$, stained for visualisation of microtubules and subjected to fluorescence confocal microscopy. Before fixation and immunostaining, the cells in $\mathrm{b}$ and $\mathrm{d}$ were subjected to microtubuledestabilisation by treatment with $4 \mu \mathrm{g} / \mathrm{ml}$ nocodazole for 1 hour. (B) Quantitative analysis of the microtubule density in MAC-B/23-5 cells. Cells were fixed, extracted with Triton X-100, double-stained for visualisation of microtubules and of murine P23 and subjected to confocal microscopy. The fluorescence intensities for both signals and the cell area were integrated using the LSM-4 software program, and the microtubule density for 25 cells was calculated as described in Materials and methods. The upper graph shows the average microtubule density for MAC-B cells (grey bar) and for MAC-B/23-5 cells (black bar) on the left. On the right, the increase in microtubule density with increasing mouse $\mathrm{P} 23$ expression levels in MAC-B/23-5 cells is demonstrated. Cells were divided into three groups with low, medium and high P23 expression, and the average P23 expression levels (open bars) and microtubule densities (black bars) are displayed for each group. The graph below shows the linear regression analysis demonstrating the relationship between the microtubule density and mouse P23 expression level in MAC-B/ 23-5 cells on a logarithmic scale basis. Note that the antipeptide antibody used for visualisation of P23 detects only the expressed murine P23 (Fig. 5A). (C) Nocodazole-destabilisation of microtubules. MAC-B cells and MAC-B/23-5 cells were either left untreated or were treated with nocodazole $(4 \mu \mathrm{g} / \mathrm{ml}$ for 1 hour $)$ and subsequently stained for visualisation of microtubules as in Ab,d. The intensity of the microtubule fluorescence signal for 20 cells per cell line and treatment was quantified and the average values were calculated. The values were normalised to compare the relative microtubule mass of MAC-B/23-5 cells (black bars) with that of MAC-B cells (open bars) for each treatment separately. Note that the absolute fluorescence intensity was much lower in nocodazole-treated cells. (D) Levels of acetylated tubulin in MAC-B cells versus MAC-B/23-5 cells. Both cell lines were grown to near-confluency on $10 \mathrm{~cm}$ dishes and lysed into SDScontaining buffer as described in the experimental section. Equal volumes of cell extracts were analysed by SDS-electrophoresis and western blotting. The blots were probed for acetylated $\alpha$-tubulin (top), for $\alpha$-tubulin (middle) and with an unrelated antibody (bottom) as a loading control. As a positive control for the acetylation reaction, MAC-B cells were treated overnight with $10 \mu \mathrm{M}$ taxol (lane 1). Untreated MAC-B cells (lane 2) and MAC-B/23-5 cells (lane 3) were analysed using the indicated antibodies. The graphs below show the relative levels for $\alpha$-tubulin and for acetylated $\alpha$-tubulin in MAC-B cells (open bars) and MAC-B/23-5 cells (black bars) obtained from scanning the signals in lanes 2 and 3, and after correction for the loading control signals. 
in Fig. 6Ab,d. Quantitative assessment of the microtubule mass from the overall microtubule fluorescence of 20 nocodazole-treated cells and an equal number of untreated cells per cell line revealed that in P23-overexpressing cells, the microtubules were considerably protected against depolymerisation by nocodazole (Fig. 6C). In another assay, we assessed the relative amount of acetylated $\alpha$-tubulin in MAC-B and MAC-B/23-5 cells by means of western blotting (Fig. 6D). The monoclonal antibody 6-11B-1 specifically detects acetylated $\alpha$-tubulin (LeDizet and Piperno, 1991) and has been used before to quantify stable microtubules (Bulinski et al., 1988). In a control experiment, MAC-B cells were treated with the microtubule-stabilising agent taxol, which resulted in a vast increase in the western blot signal from the antibody 6-11B-1 (lane 1). In contrast, the signal obtained with this antibody in untreated cells was very low compared to that for unmodified $\alpha$-tubulin (lanes 2 and 3 ). However, in each experiment, the signal was considerably higher in MAC-B/23-5 cells compared to the control MAC$\mathrm{B}$ cells. Quantification of the blots revealed that the amount of stable microtubules was about 2.5-fold higher in the MACB/23-5 cell line compared to the control cells, and the total tubulin content was increased by about $30 \%$. This is in remarkable agreement with the figures obtained by the microtubule-destabilisation assay, when the microtubule mass was estimated by confocal microscopy (cf. Fig. 6C). Thus, the data presented in this section demonstrate that elevation of intracellular P23 levels results in microtubule stabilisation.

\section{DISCUSSION}

\section{P23 binds to tubulin and associates with microtubules during specific phases of the cell cycle}

We investigated the intracellular distribution of P23 by cell fractionation and immunofluorescence microscopy. Our results demonstrated that P23 is a cytoplasmic protein which was not found in association with any organelles. In a gel filtration experiment, we showed that P23 occurs both free and in complexes of up to $150 \mathrm{kDa}$. As the complexed form was detected in the same fractions as dimeric tubulin, we investigated whether P23 can be immunoprecipitated by antitubulin antibodies, and we showed that a fraction of P23 is indeed precipitated. Although, our protocol was not suitable for obtaining quantitative data, we estimated that only about $10 \%$ of the total P23 protein was bound to the beads, indicating that the interaction is relatively weak and/or that only a small proportion of P23 is actually bound to tubulin. The latter possibility is in line with observations from the immunostaining experiments, as the excess of unbound P23 protein obscured the display of the microtubular cytoskeleton with P23 antibodies when the Triton extraction step was omitted from the immunostaining procedure (not shown).

The results of the immunofluorescence experiments provided evidence for the association of P23 with microtubules in vivo. The specificity of the immunostaining reaction was established in various control experiments, and we demonstrated the cell cycle-dependent colocalisation of P23 with microtubules both with a mouse monoclonal antibody and with an affinity-purified antipeptide antibody from rabbit. Fixation with glutaraldehyde or with formaldehyde yielded essentially the same results, whereas methanol fixation was not suitable to stabilise the interaction of P23 with microtubules sufficiently. We consistently observed two types of structural organisation of P23 protein in the cell, i.e. colocalisation with the microtubular network, typically in $\mathrm{G}_{1}, \mathrm{~S}$ and $\mathrm{G}_{2}$ phase cells (Fig. 2d,f,h), and a punctate organisation with a scarce distribution of individual signals in the cytoplasm, usually found in resting cells (Fig. $2 \mathrm{~b}$ ) and in early postmitotic cells (result not shown). Close inspection of the latter types of images at a higher magnification and at other sectioning settings of the confocal microscope revealed that these 'punctate' signals are often displayed as short string-like structures, which are likely to represent residual microtubular localisation of P23. By zscanning, the apparent nuclear staining in these images could also be resolved as residual staining of cytoskeletal structures surrounding the nucleus. Although we did observe some nuclear staining in individual cells (see e.g. Fig. 2f), this was not related to specific cell cycle phases, but is more likely to be due to incomplete removal of the unbound P23 during the extraction, considering that the relatively small protein may diffuse through the nuclear pore and may get trapped in the nucleus during the procedure. In summary, the results of our immunolocalisation studies showed that P23 is hardly found on microtubules when cells are in the resting state; however, it is present on microtubules during most phases of the cell cycle, inclusive of the mitotic spindle during metaphase. The observation that P23 is not bound to the spindle during the later mitotic phases and to microtubules in early postmitotic cells indicates that the microtubule-association of P23 is down-regulated in mitosis, presumably during metaphaseanaphase transition.

We investigated the ability of P23 to bind to tubulin by in vitro experiments using GST-P23 fusion proteins. The results of the binding studies (Figs 3A, 4C) clearly showed that P23 associates with dimeric tubulin both in cell extracts and in vitro. We also demonstrated binding of purified recombinant P23 to taxol-stabilised microtubules prepared from rat brain in vitro (Figs 3B, 4D). We found that approximately $40 \%$ of the input protein was bound to the microtubules under our conditions (result not shown), which included two washings of the microtubule pellet in a 30-fold excess of buffer each. Identification of the tubulin binding domain of mammalian P23 (Fig. 4) revealed that it represents a highly charged, mainly basic region within an otherwise very acidic protein, which shares similarity with part of the tubulin binding region of MAP-1B (Fig. 4A). The tubulin binding domain is highly conserved among the vertebrate $\mathrm{P} 23$ homologues but it does not comprise one of the two 'TCTP(P23) signatures', which were identified in the PROSITE database as areas highly conserved between P23 sequences of all eukaryotic phyla. Although there are differences between the putative tubulin binding site of mammalian P23 and the corresponding regions of yeast and plant P23, they all have the common feature of being a highly charged, basic region of the protein, with a conserved distribution of the charged amino acids. Interestingly, nearly $90 \%$ of the charged amino acids within this region are lysine and glutamic acid residues. The predominance of lysine and glutamic acid residues is also a 
typical feature of the tubulin binding region in MAP-1B, which contains reiterated KKEX motifs (Lien et al., 1994; Noble et al., 1989). These motifs appear to be important for the interaction with microtubules, in the case of both MAP1B (Noble et al., 1989) and of centromere binding proteins (Jiang et al., 1993). It seems possible that the interaction of P23 with tubulin has a similar basis.

\section{Overexpression of P23 affects cell morphology and the microtubular cytoskeleton}

To investigate the potential of P23 to modulate the microtubular cytoskeleton in vivo, we performed overexpression experiments. We estimated the endogenous P23 level by western blotting to be about $0.1 \%$ (w/w) of the soluble cellular protein, a range comparable to that of microtubuleassociated proteins (Barlow et al., 1994; Nguyen et al., 1997). A twofold increase of the total P23 level in bovine mammary epithelial cells resulted in an increase in the average cell size (Fig. 5D) and in considerable morphological alterations (Fig. 5C). The former observation could be related to the larger number of cells in the $\mathrm{S}$ and $\mathrm{G}_{2} / \mathrm{M}$ phases of the cell cycle (Fig. 5D), and the alterations of cell shape suggested that rearrangements of the microtubular cytoskeleton may have occurred. Visualisation of microtubules revealed that significant rearrangements of the microtubular network had indeed occurred (Fig. 6A), in particular a predominantly parallel orientation of microtubules compared to the more radial arrangement in the vector control cells. We frequently observed arrays of densely packaged microtubules in the cell extensions, which were reminiscent of microtubule bundles. Another type of microtubule bundling, in the form of circumferential whorls of microtubules, was observed in individual cells with high P23 expression levels, e.g. in transiently transfected COS-7 cells and in insect Sf9 cells (results not shown).

Rearrangement and bundling of microtubules is frequently observed in cells overexpressing microtubule-associated proteins (Barlow et al., 1994; Takemura et al., 1992, 1995; Umeyama et al., 1993; Weisshaar et al., 1992; reviewed by Hirokawa, 1994; Maccioni and Cambiazo, 1995; Mandelkow and Mandelkow, 1995). However, the individual MAPs differ considerably in their efficiency to induce such microtubule alterations (Barlow et al., 1994; Nguyen et al., 1997; Takemura et al., 1992; Wang et al., 1996). The effect of MAPs on the microtubular cytoskeleton is mainly attributed to their microtubule-stabilising function, which has been demonstrated both by in vitro assays (Gamblin et al., 1996; Pryer et al., 1992; Vandecandelaere et al., 1996) and in numerous overexpression studies (Lee and Rook, 1992; Takemura et al., 1992; Nguyen et al., 1997; reviewed by Hirokawa, 1994; McNally, 1996). Therefore, we asked whether the observed microtubule rearrangements in P23overexpressing cells were related to increased microtubule stability. To this end, we compared the microtubule stability in MAC-B and MAC-B/23-5 cell lines (1) by estimating the microtubule density per cell and the relative microtubule mass by confocal microscopy, (2) by assessing the amount of stabilised microtubules in a microtubule-destabilisation assay and (3) by comparing the relative amount of total tubulin and of stable microtubules by western blotting. The results of all these investigations were in good agreement and showed that the relative quantity of stable microtubules is about 2.5 -fold higher in the P23-overexpressing cell line compared to the vector control cells and that the amount of total microtubules/tubulin is about $30 \%$ higher. The effect of increase in P23 on tubulin levels is likely to be secondary to microtubule stabilisation, as tubulin synthesis is tightly regulated in relation to the total microtubule mass of the cell. We conclude from this data that P23 overexpression exerts a net stabilising effect on microtubules. The dynamic instability of microtubules results from the equilibrium of four basic processes, i.e. polymerisation, depolymerisation, catastrophe and rescue (reviewed by McNally, 1996). It remains to be investigated which of these individual processes is particularly affected by raising intracellular P23 levels. The microtubule stabilising effect of P23 observed in vivo may also be indirect, resulting from P23 interfering with processes that affect the overall microtubule stability, but are primarily mediated by other proteins. The observed alteration of cell morphology in the P23-overexpressing cells is likely to be a result of the microtubule stabilising effect, as microtubules are a major determinant for cell shape.

The results presented in this study show that P23 has tubulin binding properties, that it is found in association with tubulin or microtubules in vitro and in vivo, and that it exerts a net stabilising effect on microtubules once it is overexpressed. These observations, together with the abundance of $\mathrm{P} 23$, indicate a relationship to microtubuleassociated proteins. However, P23 is certainly not a bona fide MAP, as MAPs are about tenfold larger proteins whose affinity to microtubules is considerably higher than that of $\mathrm{P} 23$. In terms of its size, P23 is more related to the tubulin binding protein stathmin/Op18, which was recently shown to have microtubule-destabilising activity (reviewed by Lawler, 1998). It is well documented that stathmin/Op18 binds to dimeric tubulin (Jourdain et al., 1997; Curmi et al., 1997), and more recently it was reported that a subfraction of stathmin can also be found at the mitotic spindle (Gavet et al., 1998). P23 is therefore not unique in its ability to bind to both tubulin and microtubules, although this property is unusual among proteins interacting with tubulin/ microtubules. Several questions remain to be addressed in further studies. (1) At present, we cannot resolve the question of whether the P23-microtubule interaction might be mediated by other proteins, as the microtubule preparations used in this study were not free of MAPs. (2) It will be necessary to investigate, by employing more specific assays, whether P23 (overexpression) directly affects specific determinants of microtubular dynamic instability or whether it is involved in other processes, which may indirectly affect the equilibrium of microtubule dynamics.

\section{Effect of P23 overexpression on cell growth}

Our overexpression experiments also showed that elevation of intracellular P23 levels resulted in a considerable inhibition of cell growth (Fig. 5B). Previous observations demonstrated that P23 levels are positively related to cell growth. (1) The rate of P23 synthesis is up-regulated very early after growth stimulation of mammalian cells and is down-regulated in quiescent cells (Thomas, 1986; Böhm et al., 1989) and in cells under stress conditions (Bommer et al., 1994). (2) Immunohistochemical staining of whole mouse slices revealed that P23 
levels are particularly high in actively proliferating tissues, such as skin and gut (R. Benndorf and U.-A. Bommer, unpublished observation). (3) The plant homologue of P23 was found to be highly expressed in proliferating tissues of pea roots (Woo and Hawes, 1997) and in barley (K. Müller and W. Rohde, personal communication), and similar observations have been made in the polyp Hydra (L. Yan, K. Fei and M.P. Sarras Jr., personal communication). These results are in line with our findings from immunostaining experiments and from western blots (not shown) demonstrating that P23 levels increase about fourfold during the transition of cells from the resting to the growing state. The demonstration that P23 overexpression leads to growth retardation does not necessarily contradict the notion that P23 is positively involved in cell growth. In the case of various other growth-promoting gene products, both over- and underexpression often resulted in growth retardation, or even cell death.

Overexpression of the microtubule-associated protein MAP-4 has recently been shown to result in reduction of the cell growth rate (Nguyen et al., 1997), apart from interfering with intracellular vesicle transport (Bulinski et al., 1997). In the case of P23, the results of our FACS scan analysis (Fig. $5 \mathrm{D})$ indicated that overexpression may affect the progression of cells through mitosis. A delay of cell division could be explained simply by the microtubule stabilising effect of P23 inhibiting the onset of mitosis (Zhai et al., 1996). Another explanation relates to the observed binding of P23 to the mitotic spindle during metaphase. P23 might exert a specific function during mitosis requiring precise regulation of its spindle association, which may be affected by overexpression. Other proteins that have been found in association with the mitotic spindle include motor proteins (recently reviewed by Hoyt and Geiser, 1996; Hyman and Karsenti, 1996; Vernos and Karsenti, 1996; Waters and Salmon, 1997), MAPs (Anderson et al., 1994; Masson and Kreis, 1995; Vandre et al., 1991; Saunders et al., 1997; Anderson and Karsenti, 1997) and mitotic protein kinases (Glover et al., 1996; Gopalan et al., 1997; Kimura et al., 1997; Lane and Nigg, 1997). The microtubule-association of MAPs during mitosis is often regulated by phosphorylation (Brisch et al., 1996; Ookata et al., 1997; reviewed by Hirokawa, 1994; Maccioni and Cambiazo, 1995; Sorger et al., 1997), and it is likely that phosphorylation is involved in the case of P23 as well. The view that P23 may be a phosphoprotein is supported by various reports demonstrating that it occurs as different isoforms in vivo (Hughes et al., 1993; Celis et al., 1994; Walsh et al., 1995; Sanchez et al., 1997). We have obtained preliminary evidence indicating that the isoform pattern of P23 is altered during mitosis (U.-A. Bommer, I. Demalte and J.-C. Sanchez, unpublished observation) and that P23 is phosphorylated by a mitotic kinase activity in vitro (results not shown).

In this paper, we describe the properties of the growthrelated protein P23 as a tubulin binding protein, which is temporarily associated with microtubules and the spindle apparatus. Our overexpression data show that elevation of P23 levels leads to microtubule stabilisation, to alterations of cell morphology and to distortions in the cell division process. Further investigations will be necessary to identify the precise role of P23 during its association with microtubules and with the mitotic spindle.
The authors wish to thank Miss B. Sawitzki (Berlin) who performed important initial experiments on the subcellular localisation of P23 in our laboratory. The help of Dr P. Bourdelow (London) in preparing truncated mutants of GST-P23 fusion proteins is highly appreciated. We thank Mr. J. Tyzack (Dundee) for his help in performing the gel filtration experiment. Drs. V. Baldin (Toulouse), M. Gaestel (Berlin) and D. Templeton (Cleveland) provided valuable cDNA clones. Antibodies were obtained from Drs S. Goodbourn (London), P. Gordon-Weeks (London) and J.-C. Sanchez (Geneva). Dr D. Schaller (Geneva) provided purified recombinant human and His-tagged yeast P23 protein, and antibodies. We are indebted to Mr S. Ribeiro (London) for performing the statistical analyses. Dr M. Peitsch (Swissprot BioComputing Service at Glaxo Institute for Molecular Biology, Geneva) provided services for sequence searches in databases. We thank Drs M. Clemens, P. Gordon-Weeks, J. Hyams and C. Proud for helpful discussions or comments on the manuscript. This work was funded by a research grant from the Wellcome Trust to U.A.B. The contribution by the Cancer Prevention Research Trust is highly appreciated. M.L. was supported by a Studentship from St George's Hospital Medical School.

\section{REFERENCES}

Adams, M. D., Kerlavage, A. R., Fleischmann, R. D., Fuldner, R. A., Bult, C. J., Lee, N. H., Kirkness, E. F., Weinstock, K. G., Gocayne, J. D., White, O., et al. (1995). Initial assessment of human gene diversity and expression pattern based upon 83 million nucleotides of cDNA sequence. Nature 377(6547S), 3-174

Anderson, S. S. L., Buendia, B., Dominguez, J. E., Sawyer, A. and Karsenti, E. (1994). Effect on microtubule dynamics of XMAP230, a microtubule-associated protein present in Xenopus laevis eggs and dividing Cells. J. Cell Biol. 127, 1289-1299.

Andersen, S. S. and Karsenti, E. (1997). XMAP310: a Xenopus rescuepromoting factor localised to the mitotic spindle. J. Cell Biol. 139, 975983

Barlow, S., Gonzalez-Garay, M. L., West, R. R., Olmsted, J. B. and Cabral, F. (1994). Stable expression of heterologous microtubule-associated proteins (MAPs) in Chinese hamster ovary cells: evidence for differing roles of MAPs in microtubule organisation. J. Cell Biol. 126, 1017-1029.

Benndorf, R., Nürnberg, P. and Bielka, H. (1988). Growth phase-dependent proteins of the Ehrlich ascites tumor analysed by one- and two-dimensional electrophoresis. Exp. Cell Res. 174, 130-138.

Bhisutthibhan, J., Pan, X. Q., Hossler, P. A., Walker, D. J., Yowell, C. A., Carlton, J., Dame, J. B. and Meshnick, S. R. (1998). The Plasmodium falciparum translationally controlled tumor protein homologue and its reaction with the antimalarial drug artemisinin. J. Biol. Chem. 273, 1619216198.

Böhm, H., Benndorf, R., Gaestel, M., Gross, B., Nürnberg, P., Kraft, R., Otto, A. and Bielka, H. (1989). The growth-related protein P23 of the Ehrlich ascites tumor: translational control, cloning and primary structure. Biochem. Int. 19, 277-286.

Böhm, H., Gross, B., Gaestel, M., Bommer, U. A., Ryffel, G. and Bielka, H. (1991). The 5'-untranslated region of p23 mRNA from the Ehrlich ascites tumor is involved in translation control of the growth related protein p23. Biomed. Biochim. Acta 50, 1193-1203.

Bommer, U. A., Lutsch, G., Behlke, J., Stahl, J., Nesytova, N., Henske, A. and Bielka, H. (1988). Shape and location of eukaryotic initiation factor eIF-2 on the $40 \mathrm{~S}$ ribosomal subunit of rat liver. Immunoelectronmicroscopic and hydrodynamic investigations. Eur. J. Biochem. 172, 653662.

Bommer, U. A., Lazaris-Karatzas, A., De Benedetti, A., Nürnberg, P., Benndorf, R., Bielka, H. and Sonenberg, N. (1994). Translational regulation of the mammalian growth-related protein P23: involvement of eIF-4E. Cell. Mol. Biol. Res. 40, 633-641.

Brisch, E., Daggett, M. A. F. and Suprenant, K. A. (1996). Cell cycledependent phosphorylation of the $77 \mathrm{kDa}$ echinoderm microtubuleassociated protein (EMAP) in vivo and association with the p34 cdc2 kinase. J. Cell Sci. 109, 2885-2893.

Bulinski, J. C., Richards, J. E. and Piperno, G. (1988). Posttranslational modifications of $\alpha$-tubulin: Detyrosination and acetylation differentiate 
populations of interphase microtubules in cultured cells. J. Cell Biol. 106, 1213-1220.

Bulinski, J. C., McGraw, T. E., Gruber, D., Nguyen, H. L. and Sheetz, M. P. (1997). Overexpression of MAP4 inhibits organelle motility and trafficking in vivo. J. Cell Sci. 110, 3055-3064.

Celis, J. E., Rasmussen, H. H., Olsen, E., Madsen, P., Leffers, H., Honore, B., Dejgaard, K., Gromov, P., Vorum, H., Vassilev, A., et al. (1994). The human keratinocyte two-dimensional protein database (update 1994): towards an integrated approach to the study of cell proliferation, differentiation and skin diseases. Electrophoresis 15, 1349-1458.

Chitpatima, S. T., Makrides, S., Bandyopadhyay, R. and Brawerman, G. (1988). Nucleotide sequence of a major messenger RNA for a 21 kilodalton polypeptide that is under translational control in mouse tumor cells. Nucleic Acids Res. 16, 2350.

Curmi, P. A., Andersen, S. S., Lachkar, S., Gavet, O., Karsenti, E., Knossow, M. and Sobel, A. (1997). The stathmin/tubulin interaction in vitro. J. Biol. Chem. 272, 25029-25036.

Gamblin, T. C., Nachmanoff, K., Halpain, S. and Williams, R. C. (1996). Recombinant microtubule-associated protein $2 \mathrm{C}$ reduces the dynamic instability of individual microtubules. Biochemistry 35, 12576-12586.

Gavet, O., Ozon, S., Manceau, V., Lawler, S., Curmi, P. and Sobel, A. (1998). The stathmin phosphoprotein family: intracellular localization and effects on the microtubule network. J. Cell Sci. 111, 3333-3346.

Glover, D. M., Ohkura, H. and Tavares, A. (1996). Polo kinase: The choreographer of the mitotic stage. J. Cell Biol. 135, 1681-1684.

Gopalan, G., Chan, C. S. M. and Donovan, P. J. (1997). A novel mammalian, mitotic spindle-associated kinase is related to yeast and fly chromosome segregation regulators. J. Cell Biol. 138, 643-656.

Gross, B., Gaestel, M., Böhm, H. and Bielka, H. (1989). cDNA sequence coding for a translationally controlled human tumor protein. Nucleic Acids Res. 17, 8367.

Haghighat, N. G. and Ruben, L. (1992). Purification of novel calcium binding proteins from Trypanosoma brucei: properties of 22-, 24- and 38kilodalton proteins. Mol. Biochem. Parasitol. 51, 99-110.

Hirokawa, N. (1994). Microtubule organisation and dynamics dependent on microtubule- associated proteins. Curr. Opin. Cell Biol. 6, 74-81.

Hoyt, M. A. and Geiser, J. R. (1996). Genetic analysis of the mitotic spindle. Annu. Rev. Genet. 30, 7-33.

Hughes, G. J., Frutiger, S., Paquet, N., Pasquali, C., Sanchez, J. C., Tissot, J. D., Bairoch, A., Appel, R. D. and Hochstrasser, D. F. (1993). Human liver protein map: update 1993. Electrophoresis 14, 1216-1222.

Huynh, H. T., Robitaille, G. and Turner, J. D. (1991). Establishment of bovine mammary epithelial cells (MAC-T): an in vitro model for bovine lactation. Exp. Cell Res. 197, 191-199.

Hyman, A. A. and Karsenti, E. (1996). Morphogenetic properties of microtubules and mitotic spindle assembly. Cell 84, 401-410.

Jiang, W., Middleton, K., Yoon, H. J., Fouquet, C. and Carbon, J. (1993). An essential yeast protein, CBF5p, binds in vitro to centromeres and microtubules. Mol. Cell. Biol. 13, 4884-4893.

Jourdain, L., Curmi, P., Sobel, A., Pantaloni, D. and Carlier, M. F. (1997). Stathmin: a tubulin-sequestering protein which forms a ternary T2S complex with two tubulin molecules. Biochemistry 36, 10817-10821.

Kimura, M., Kotani, S., Hattori, T., Sumi, N., Yoshioka, T., Todokoro, K. and Okano, Y. (1997). Cell cycle-dependent expression and spindle pole localization of a novel human protein kinase, aik, related to aurora of Drosophila and yeast Ipl1. J. Biol. Chem. 272, 13766-13771.

Lane, H. A. and Nigg, E. A. (1997). Cell-cycle control: Polo-like kinases join the outer circle. Trends Cell Biol. 7, 63-68.

Lawler, S. (1998). Microtubule dynamics: If you need a shrink try stathmin/Op18. Curr. Biol. 8, R212-R214.

LeDizet, M. and Piperno, G. (1991). Detection of acetylated $\alpha$-tubulin by specific antibodies. Methods Enzymol. 196, 264-274.

Lee, G. and Rook, S. L. (1992). Expression of tau protein in non-neuronal cells: microtubule binding and stabilization. J. Cell Sci. 102, 227-237.

Lien, L. L., Feener, C. A., Fischbach, N. and Kunkel, L. M. (1994). Cloning of human microtubule-associated protein $1 \mathrm{~B}$ and the identification of a related gene on chromosome 15. Genomics 22, 273-280.

Maccioni, R. B. and Cambiazo, V. (1995). Role of microtubule-associated proteins in the control of microtubule assembly. Physiol. Rev. 75, 835-864.

MacDonald, S. M., Rafnar, T., Langdon, J. and Lichtenstein, L. M. (1995). Molecular identification of an IgE-dependent histamine-releasing factor. Science 269, 688-690.

Mandelkow, E. and Mandelkow, E. M. (1995). Microtubules and microtubule-associated proteins. Curr. Opin. Cell Biol. 7, 72-81.
Masson, D. and Kreis, T. E. (1995). Binding of E-MAP-115 to microtubules is regulated by cell cycle-dependent phosphorylation. J. Cell Biol. 131, 1015-1024.

McNally, F. J. (1996). Modulation of microtubule dynamics during the cell cycle. Curr. Opin. Cell Biol. 8, 23-29.

Nguyen, H. -L., Chari, S., Gruber, D., Lue, C.-M., Chapin, S. J. and Bulinski, J. C. (1997). Overexpression of full- or partial length MAP4 stabilises microtubules and alters cell growth. J. Cell Sci. 110, 281-294.

Nielsen, H. V., Johnsen, A. H., Sanchez, J. C., Hochstrasser, D. F. and Schiotz, P. O. (1998). Identification of a basophil leukocyte interleukin-3regulated protein that is identical to IgE-dependent histamine-releasing factor. Allergy 53, 642-652.

Noble, M., Lewis, S. A. and Cowan, N. J. (1989). The microtubule binding domain of microtubule-associated protein MAP1B contains a repeated sequence motif unrelated to that of MAP2 and tau. J. Cell Biol. 109, 33673376.

Ookata, K., Hisanaga, S., Sugita, M., Okuyama, A., Murofushi, H., Kitazawa, H., Chari, S., Bulinski, J. C. and Kishimoto, T. (1997). MAP4 is the in vivo substrate for CDC-2 kinase in HeLa cells: Identification of an M-phase specific and a cell cycle-independent phosphorylation site. Biochemistry 36, 15873-15883.

Pryer, N. K., Walker, R. A., Skeen, V. P., Bourns, B. D., Soboeiro, M. F. and Salmon, E. D. (1992). Brain microtubule-associated proteins modulate microtubule dynamic instability in vitro. Real-time observations using video microscopy. J. Cell Sci. 103, 965-976.

Sage-Ono, K., Ono, M., Harada, H. and Kamada, H. (1998). Darkinduced accumulation of mRNA for a homologue of translationally controlled tumour protein (TCTP) in Pharbitis. Plant Cell Physiol. 39, 357-360.

Sanchez, J. C., Schaller, D., Ravier, F., Golaz, O., Jaccoud, S., Belet, M., Wilkins, M. R., James, R., Deshusses, J. and Hochstrasser, D. F. (1997) Translationally controlled tumour protein: A protein identified in several nontumoral cells including erythrocytes. Electrophoresis 18, 150-157.

Saunders, R. D. C., Avides, M. D., Howard, T., Gonzalez, C. and Glover, D. M. (1997). The Drosophila gene abnormal spindle encodes a novel microtubule-associated protein that associates with the polar regions of the mitotic spindle. J. Cell Biol. 137, 881-890.

Schroeder, J. T., Lichtenstein, L. M. and MacDonald, S. M. (1996). An immunoglobulin E-dependent recombinant histamine-releasing factor induces interleukin-4 secretion from human basophils. J. Exp. Med. 183, $1265-1270$

Sorger, P. K., Dobles, M., Tournebize, R. and Hyman A. A. (1997). Coupling cell division and cell death to microtubule dynamics. Curr. Opin. Cell Biol. 9, 807-14.

Stürzenbaum, S. R., Kille, P. and Morgan, A. J. (1998). Identification of heavy metal induced changes in the expression patterns of the translationally controlled tumour protein (TCTP) in the earthworm Lumbricus rubellus 1. Biochim. Biophys. Acta 1398, 294-304.

Takemura, R., Okabe, S., Umeyama, T., Kanai, Y., Cowan, N. J. and Hirokawa, N. (1992). Increased microtubule stability and alpha tubulin acetylation in cells transfected with microtubule-associated proteins MAP1B, MAP2 or tau. J. Cell Sci. 103, 953-964.

Takemura, R., Okabe, S., Umeyama, T. and Hirokawa, N. (1995). Polarity orientation and assembly process of microtubule bundles in nocodazole-treated, MAP2c-transfected COS cells. Mol. Biol. Cell 6, 981 996.

Thiele, H., Berger, M., Lenzner C., Kuhn, H. and Thiele, B. J. (1998). Structure of the promoter and complete sequence of the gene coding for the rabbit translationally controlled tumor protein (TCTP) P23. Eur J. Biochem. 257, 62-68

Thomas, G. (1986). Translational control of mRNA expression during the early mitogenic response in Swiss mouse 3T3 cells: identification of specific proteins. J. Cell Biol. 103, 2137-2144.

Thomas, G. and Luther, H. (1981). Transcriptional and translational control of cytoplasmic proteins after serum stimulation of quiescent Swiss $3 \mathrm{~T} 3$ cells. Proc. Natl. Acad. Sci. USA 78, 5712-5716.

Umeyama, T., Okabe, S., Kanai, Y. and Hirokawa, N. (1993). Dynamics of microtubules bundled by microtubule associated protein 2C (MAP2C). $J$. Cell Biol. 120, 451-465.

Vallee, R. B. (1986). Purification of brain microtubules and microtubuleassociated protein 1 using taxol. Methods Enzymol. 134, 104-115.

Vallee, R. B. and Collins, C. A. (1986). Purification of microtubules and microtubule-associated proteins from sea urchin eggs and cultured mammalian cells using taxol, and use of exogenous taxol-stabilised brain 
microtubules for purifying microtubule-associated proteins. Methods Enzymol. 134, 116-127.

Vandecandelaere, A., Pedrotti, B., Utton, M. A., Calvert, R. A. and Bayley, P. M. (1996). Differences in the regulation of microtubule dynamics by microtubule-associated proteins MAP1B and MAP2. Cell Motil. Cytoskel. 35, 134-146.

Vandre, D. D., Centonze, V. E., Peloquin, J., Tombes, R. M. and Borisy, G. G. (1991). Proteins of the mammalian mitotic spindle: phosphorylation/dephosphorylation of MAP-4 during mitosis. J. Cell Sci. 98, 577-588.

Vernos, I. and Karsenti, E. (1996). Motors involved in spindle assembly and chromosome segregation. Curr. Opin. Cell Biol. 8, 4-9.

Walsh, B. J., Gooley, A. A., Williams, K. L. and Breit, S. N. (1995). Identification of macrophage activation associated proteins by twodimensional gel electrophoresis and microsequencing. J. Leukoc. Biol. 57, 507-512.

Wang, X. M., Peloquin, J. G., Zhai, Y., Bulinski, J. C. and Borisy, G. G. (1996). Removal of MAP4 from microtubules in vivo produces no observable phenotype at the cellular level. J. Cell Biol. 132, 345-357.
Waters, J. C. and Salmon, E. D. (1997). Pathways of spindle assembly. Curr. Opin. Cell Biol. 9, 37-43.

Weisshaar, B., Doll, T. and Matus, A. (1992). Reorganisation of the microtubular cytoskeleton by embryonic microtubule-associated protein 2 (MAP2c). Development 116, 1151-1161.

Woo, H. H. and Hawes, M. C. (1997). Cloning of genes whose expression is correlated with mitosis and localised in dividing cells in root caps of Pisum sativum L. Plant Mol. Biol. 35, 1045-1051.

Yenofsky, R., Bergmann, I. and Brawerman, G. (1982). Messenger RNA species partially in a repressed state in mouse sarcoma ascites cells. Proc. Natl. Acad. Sci. USA 79, 5876-5880.

Yenofsky, R., Cereghini, S., Krowczynska, A. and Brawerman, G. (1983). Regulation of mRNA utilization in mouse erythroleukemia cells induced to differentiate by exposure to dimethyl sulfoxide. Mol. Cell. Biol. 3, 11971203

Zhai, Y., Kronebusch, P. J., Simon, P. M. and Borisy, G. G. (1996). Microtubule dynamics at the $\mathrm{G}_{2} / \mathrm{M}$ transition: Abrupt breakdown of cytoplasmic microtubules at nuclear envelope breakdown and implications for spindle morphogenesis. J. Cell Biol. 135, 201-214. 